OPEN ACCESS

Edited by:

Johannes Grillari,

Ludwig Boltzmann Institute

for Experimental and Clinical

Traumatology, Austria

Reviewed by:

Janina Burk,

University of Giessen, Germany

Bruna Corradetti,

Houston Methodist Research

Institute, United States

${ }^{*}$ Correspondence:

Valentina Saccone

valentina.saccone@unicatt.it;

v.saccone@hsantalucia.it

${ }^{\dagger}$ These authors have contributed equally to this work

Specialty section:

This article was submitted to Preclinical Cell and Gene Therapy,

a section of the journal

Frontiers in Bioengineering and

Biotechnology

Received: 13 January 2021 Accepted: 01 April 2021

Published: 13 May 2021

Citation:

Sandonà M, Di Pietro L, Esposito F, Ventura A, Silini $A R$, Parolini O and Saccone V (2021) Mesenchymal Stromal Cells and Their Secretome: New Therapeutic Perspectives for Skeletal Muscle Regeneration

Front. Bioeng. Biotechnol. 9:652970. doi: 10.3389/fbioe.2021.652970

\section{Mesenchymal Stromal Cells and Their Secretome: New Therapeutic Perspectives for Skeletal Muscle Regeneration}

\author{
Martina Sandonà $1 t$, Lorena Di Pietro ${ }^{2 t}$, Federica Esposito', Alessia Ventura', \\ Antonietta Rosa Silini ${ }^{3}$, Ornella Parolini ${ }^{2,4}$ and Valentina Saccone ${ }^{1,2 *}$ \\ ${ }^{1}$ Istituto di Ricovero e Cura a Carattere Scientifico (IRCCS), Fondazione Santa Lucia, Rome, Italy, ${ }^{2}$ Dipartimento di Scienze \\ della Vita e Sanità Pubblica, Università Cattolica del Sacro Cuore, Rome, Italy, ${ }^{3}$ Centro di Ricerca "E. Menni", Fondazione \\ Poliambulanza - Istituto Ospedaliero, Brescia, Italy, ${ }^{4}$ Fondazione Policlinico Universitario "Agostino Gemelli" IRCCS, Rome, \\ Italy
}

Mesenchymal stromal cells (MSCs) are multipotent cells found in different tissues: bone marrow, peripheral blood, adipose tissues, skeletal muscle, perinatal tissues, and dental pulp. MSCs are able to self-renew and to differentiate into multiple lineages, and they have been extensively used for cell therapy mostly owing to their anti-fibrotic and immunoregulatory properties that have been suggested to be at the basis for their regenerative capability. MSCs exert their effects by releasing a variety of biologically active molecules such as growth factors, chemokines, and cytokines, either as soluble proteins or enclosed in extracellular vesicles (EVs). Analyses of MSC-derived secretome and in particular studies on EVs are attracting great attention from a medical point of view due to their ability to mimic all the therapeutic effects produced by the MSCs (i.e., endogenous tissue repair and regulation of the immune system). MSCEVs could be advantageous compared with the parental cells because of their specific cargo containing mRNAs, miRNAs, and proteins that can be biologically transferred to recipient cells. MSC-EV storage, transfer, and production are easier; and their administration is also safer than MSC therapy. The skeletal muscle is a very adaptive tissue, but its regenerative potential is altered during acute and chronic conditions. Recent works demonstrate that both MSCs and their secretome are able to help myofiber regeneration enhancing myogenesis and, interestingly, can be manipulated as a novel strategy for therapeutic interventions in muscular diseases like muscular dystrophies or atrophy. In particular, MSC-EVs represent promising candidates for cell free-based muscle regeneration. In this review, we aim to give a complete picture of the therapeutic properties and advantages of MSCs and their products (MSCderived EVs and secreted factors) relevant for skeletal muscle regeneration in main muscular diseases.

Keywords: mesenchymal stromal cells, secretome, extracellular vesicles, muscle, muscle regeneration, atrophy, muscular dystrophy 


\section{INTRODUCTION}

Mesenchymal "stromal" cells (MSCs) are adult, multipotent non-hematopoietic stem cells (Dominici et al., 2006). Over the last years, MSCs have emerged as a promising tool for cell therapy due to numerous features: their ability to self-renew and differentiate into several cell lineages, their ability to migrate to target tissues, and their immunomodulatory and anti-fibrotic properties, which can be attributed to their ability to secrete a plethora of biologically active molecules.

MSCs and/or mesenchymal-like cells can be isolated from numerous adult and perinatal tissues. MSCs were originally extracted from the bone marrow (Friedenstein et al., 1974) but have now been isolated from different sources: skeletal muscle (Kisiel et al., 2012), adipose tissue (Zuk et al., 2002), synovial membranes (De Bari et al., 2001), dental pulp (Rajendran et al., 2013), periodontal ligaments (Otabe et al., 2012), cervical tissue (Montesinos et al., 2013), peripheral blood (Longhini et al., 2019), suture mesenchyme of the skull (Lattanzi et al., 2013; Di Pietro et al., 2020), menstrual blood (Ren et al., 2016), perinatal tissues (Silini et al., 2015), and fetal blood (Campagnoli et al., 2001).

The International Society for Cellular Therapy (ISCT) established the minimal criteria necessary to identify MSCs: plastic adherence; positive for CD105, CD73, and CD90 surface markers; and negative ( $<2 \%$ expression) for CD11b, CD14, CD34, CD45, CD79a or CD19, and HLA class II (Dominici et al., 2006). Moreover, as multipotent cells, they must have the ability to differentiate into osteoblasts, adipocytes, and chondroblasts in in vitro differentiation conditions (Dominici et al., 2006). According to a few studies, MSCs can also express embryonic stem cell markers, such as Oct-4, Rex-1, and Sox-2 (Izadpanah et al., 2006; Riekstina et al., 2009). In 2008, similar criteria were established for MSCs from fetal membranes, with the addition that MSCs from fetal membranes must be of fetal origin (Parolini et al., 2008).

MSCs have gained much attention due to their in vitro and in vivo immunoregulatory capabilities that make them useful as guardians against excessive inflammatory responses (Prockop and Youn Oh, 2012; Magatti et al., 2017). Their protective and regenerative properties, as well as their immunoregulation skills, make them a valuable therapeutic strategy both for regenerative medicine and for the treatment of disorders characterized by alterations of the immune system.

MSCs have been shown to exert most of their effects through the release of molecules with paracrine and anti-inflammatory effects (Galderisi and Giordano, 2014). For this reason, more recently, different studies have focused on the secretome of MSCs, the set of biologically active molecules and extracellular vesicles (EVs) that these cells release. The secretome is nowadays considered a possible substitute for MSCs in cell therapy due to its comparable ability to enhance/favor tissue regeneration and modulate the immune response (Eleuteri and Fierabracci, 2019).

A hallmark in the study of the MSC secretome [or conditioned medium $(\mathrm{CM})$ ] was reached by Timmers and collaborators who fractionated the CM-MSC and discovered that the 50- to 200$\mathrm{nm}$ component was the one with the most activity (Timmers et al., 2007). Subsequent characterization studies identified this fraction as EVs, which are lipid endogenous nanoparticles that mediate the transfer of their content across cellular boundaries (Guescini et al., 2010; Andaloussi et al., 2013; Romancino et al., 2013; Forterre et al., 2014).

$\mathrm{EV}$ is the generic term accepted by the International Society for Extracellular Vesicles (ISEV) to describe vesicles, characterized by the absence of a nucleus and the inability to replicate, that are released by cells into the extracellular space (Théry et al., 2018).

EVs are found in several biological fluids such as blood, urine, saliva, amniotic fluid, and milk (Iraci et al., 2016), and they can interact with the recipient cell by direct binding or ligand-receptor binding (Kahroba et al., 2019). EVs released by cells can be classified into different subtypes based on their physical features such as size or density. Small EVs (sEVs) have a typical size lower than $200 \mathrm{~nm}$, while medium/large vesicles are characterized by a size greater than $200 \mathrm{~nm}$. The classification of EVs is also based on their biochemical composition: the presence of transmembrane or glycosylphosphatidylinositol (GPI)-anchored proteins (e.g., CD63, CD81, and MHC class I), cytosolic proteins or periplasmic proteins (e.g., TSG101, Flotillin1, Alix, and HSP-70), and proteins associated with non-EV structures (e.g., albumin and ApoA1/2).

EVs are characterized by a specific cargo composed of mRNAs, microRNAs (miRs), proteins, or DNA. This genetic material is protected by the oxidative extracellular environment and can be shuttled to distant cells in order to modulate the repair of damaged tissue (Cantaluppi et al., 2012; Borges et al., 2013).

In this review, we summarize the current research in the use of MSCs and of their secreted factors as alternative therapeutic strategies to improve skeletal muscle regeneration in the context of several muscle diseases. The MSC immune-modulatory and anti-fibrotic properties represent an attractive strategy to counteract the progression of chronic and in some cases lethal muscle diseases by reducing inflammation and fibrosis and stimulating the regenerative potential of muscle stem cells.

\section{THERAPEUTIC POTENTIAL OF MESENCHYMAL STROMAL CELLS IN SKELETAL MUSCLE REGENERATION}

The skeletal muscle is an adaptive tissue able to regenerate following damage due to trauma or genetic conditions. A complex stem cell niche resides in the muscle in which several cell types cooperate to regulate the balance between quiescence/activation/differentiation of the resident muscle stem cells, namely, satellite cells (MuSCs). In recent years, the role of other cell types has emerged, including inflammatory cells (Kharraz et al., 2013; Tidball et al., 2014) and mesenchymal cells residing in the muscle interstitium named fibro-adipogenic progenitors (FAPs), which maintain the homeostasis of the muscle niche and cooperate to support muscle regeneration (Mitchell et al., 2010; Uezumi et al., 2010, 2011; Malecova and Puri, 2012). For this reason, the muscle niche is a complex setting with different protagonists: FAPs play a pivotal role in coordinating tissue regeneration by supporting MuSC activity 
and by cooperating with inflammatory cells that mediate the activation of the regenerative response (Mozzetta et al., 2013; Madaro et al., 2018). During acute muscle injury, the myogenic program is properly activated, and inflammatory and muscle resident cells play a central role in modulating repair and regeneration; but, on the other hand, this does not occur during chronic injuries, in which myogenic regeneration is deregulated. Muscle degeneration, observed in chronic muscular injury diseases such as Duchenne muscular dystrophy (DMD), is in fact characterized by a gradual decline of regenerative potential.

DMD is the most severe muscular genetic disease in which the loss of dystrophin in the muscle leads to myofiber fragility and successive cycles of muscle necrosis and regeneration. Over time, the capacity of dystrophic muscle to regenerate becomes impaired, and muscle quality declines on account of increased fibrosis and adipose tissue deposition due to an abnormal persistence of FAPs. Indeed, the detrimental environment due to disease causes a decreased ability of MuSCs to replace degenerating muscles and an increase in the fibro-adipogenic activity of FAPs, the latter of which has proven to be a source of pro-atrophic and pro-fibrotic signals. In this dramatic context, the crosstalk between the different cell populations fails, and the regeneration ability of the entire tissue is hampered leading to muscle atrophy (Mozzetta et al., 2013; Madaro et al., 2018).

Several efforts have been devoted to the identification of effective treatments able to support the regeneration of skeletal muscle in both acute and chronic conditions. MSCs from different tissues are being studied for their ability to regenerate or repair skeletal muscle. In particular, MSCs are able to induce the proliferation and differentiation of resident MuSCs and are also able to act on the other cellular components of the muscle cell niche by reducing inflammation and infiltration.

In the following sections, we will describe evidence of the therapeutic effects of MSCs in different preclinical models of skeletal muscle injury. We will first focus on studies on acute muscle injury models in which skeletal muscle tissue is physiologically induced to activate a myogenic program and, then, on chronic pathologic damage associated with different diseases.

\section{Acute Muscle Injuries}

Skeletal muscle is a tissue with a great regenerative capacity; but if profoundly scratched due to car accidents or sport injuries, it recovers only $50 \%$ in strength and $80 \%$ of its ability to shorten (Noonan and Garrett, 1999). Up to 20\% of muscle mass loss can be compensated by the high adaptability and regenerative potential of skeletal muscle (Liu et al., 2018).

MSCs can be used to regenerate or repair skeletal muscle that has been damaged by acute injuries.

MSCs from the bone marrow (BM-MSCs) were the first and are the most studied. Intramuscular transplantation of BM-MSCs in rats with severe muscle injury has been shown to contribute to skeletal muscle healing by downregulating inflammatory cytokines levels [interleukin (IL)-1b, IL-6, TNF- $\alpha$, and IFN- $\alpha$ ] and by inducing anti-inflammatory cytokines (IL-10) (Helal et al., 2016). In addition, when compared with untreated controls, BM-MSC-treated muscles were characterized by the presence of regenerating myofibers and angiogenesis restoration (Helal et al., 2016). Moreover, BM-MSC transplantation has been shown to counteract the accumulation of fibrotic tissue in injured muscles by inhibiting the downstream signaling of the pro-fibrotic cytokine transforming growth factor beta 1 (TGF$\beta 1$ ) (Helal et al., 2016). Additionally, allogeneic BM-MSCs have also been shown to support the formation of new muscle fibers (Andrade et al., 2015) when directly injected in the muscles of rats with acute damage. The results showed an acceleration of muscle function recovery (Andrade et al., 2015).

Interestingly, in addition to BM-MSCs, adipose tissue-derived MSCs (AT-MSCs) and synovial membrane-derived MSCs (SMMSCs) have also been shown to be active contributors to skeletal muscle regeneration (De La Garza-Rodea et al., 2012). More in detail, De la Garza-Rodea and collaborators demonstrated that all three types of MSCs were able to contribute to skeletal muscle regeneration in the cardiotoxin-injured mouse (CTX mouse), a model of acute damage in the skeletal muscle tissue (De La Garza-Rodea et al., 2012). However, they demonstrated enhanced effects of AT-MSCs on myofiber formation/regeneration when compared with BM-MSCs, and this was attributed to higher engraftment in the tibialis anterior muscles (De La Garza-Rodea et al., 2012).

The regenerative effects of both allogenic BM-MSCs and ATMSCs were also described in the treatment of skeletal muscle laceration injury in Wistar rats (Moussa et al., 2020). In particular, both types of MSCs were shown to be effective and lasted up to 8 weeks post treatment, even if intramuscular injection of AT-MSCs displayed a stronger effect leading to an increase of myotube formation in parallel to a decrease of collagen deposition (Moussa et al., 2020). Similar results were obtained after immortalized BM-MSCs embedded within Pluronic F-127 hydrogel were locally injected in a muscle contusion murine model (Chiu et al., 2020). As a matter of fact, mice treated with BM-MSCs embedded in the hydrogel displayed numerous regenerating myofibers, as well as improved muscle strength, when compared with the control group (Chiu et al., 2020).

The long-term effects of the local injection of autologous BM-MSCs, combined with plastic surgery, to treat muscle necrosis were also recently investigated in a pig model of severe radiation burn (Linard et al., 2018). Very interestingly, BM-MSC treatment supported muscle regeneration even 1 year after surgery, leading to the restoration of myofiber diameter and density, stimulation of fast-twitch to slow-twitch fiber conversion, accelerated restoration of vascular structures, and regulation of M1/M2 macrophage balance in the muscle (Linard et al., 2018).

Intriguingly, transplantation of Wharton's jelly-derived MSCs (WJ-MSCs) in a mouse model of skeletal muscle injury was shown to attenuate neutrophil-mediated acute inflammation post injury and to reduce fibrous tissue accumulation by modulating TGF- $\beta 1$ levels in the muscle ( $\mathrm{Su}$ et al., 2019). The effects of WJ-MSCs were also evaluated by Kwon and colleagues who reported anti-apoptotic properties of WJ-MSCs exerted in a mouse skeletal myoblast cell line (C2C12) (Kwon et al., 2016). They demonstrated that when co-cultured in serum-deprived with $\mathrm{C} 2 \mathrm{C} 12$, WJ-MSCs secrete high levels of the chemokine 
CXCL1 (Chemokine C Motif Ligand 1) that was responsible for the anti-apoptotic effect of human WJ-MSCs (Kwon et al., 2016).

Taken together, these studies sustain the therapeutic efficacy of MSCs derived from different sources and demonstrate that they promote muscle regeneration in different animal models of acute muscle injury. Comparative studies have demonstrated the great effectiveness of MSCs in different directions: inducing new muscle fibers; decreasing inflammation by acting on cytokines, neutrophils, and macrophages; decreasing fibrosis by the modulation of TGF- $\beta 1$ levels in muscles; increasing vascularization; and improving also muscle functionality. Very interestingly, a long-term beneficial effect upon MSC transplantation has also been observed, further supporting future translation into the clinical practice.

\section{Chronic Muscle Injuries}

MSCs have been also applied as a therapeutic strategy to promote muscle regeneration in the presence of conditions due to genetic alterations (i.e., muscular dystrophies).

Seminal works have discovered that BM-MSCs have the intriguing potential to induce skeletal muscle regeneration in the mdx mouse, a model for DMD, in which mutations in exon 23 of the dystrophin gene lead to the protein deletion, thus mimicking the human pathology characterized by progressive muscle degeneration. As a matter of fact, when injected intraperitoneally into the $\mathrm{mdx}$ mouse, BM-MSCs, isolated from the femoral and tibial bone marrow of dystrophin/utrophin double-knockout mice, were able to improve disease symptoms by increasing locomotor activity and prolonging mouse survival (Maeda et al., 2017). Noteworthy, BM-MSC transplantation also increased the number of MuSCs and significantly decreased fibrosis in the diaphragm (one of the most affected organs in DMD). Furthermore, when MuSCs were co-cultured with BMMSCs, an improvement of myotube differentiation was observed (Maeda et al., 2017).

The therapeutic potential of BM-MSCs in dystrophin/utrophin double-knockout mice was also previously reported (Li et al., 2011). BM-MSC administration via the caudal vein ameliorated the symptoms, strengthened the muscle functionality, and, noteworthy, induced the expression of dystrophin and utrophin genes in the treated mice (Li et al., 2011).

A recent work reported the beneficial effects of intravenous injection of WJ-MSCs in the $\mathrm{mdx}$ mouse model (Choi et al., 2020). Indeed, treatment determined a decrease of fibrosis and of the percentage of necrotic fibers (Choi et al., 2020). The authors also indicated the paracrine secretion of the matrix metalloproteinase-1 (MMP-1) as the key factor that exerted the anti-fibrotic effect of WJ-MSCs in the muscle (Choi et al., 2020).

The ability of AT-MSCs to promote skeletal muscle regeneration in dystrophin-deficient mice was also demonstrated (Pinheiro et al., 2012). Local injection of AT-MSCs improved muscle strength and resistance to fatigue, and this was mediated by modulation of inflammation and regulation of different genes involved in the regenerative process [i.e., myogenin, vascular endothelial growth factor (VEGF), TGF- $\beta 1$, IL-6, IL-10, and IL-4] (Pinheiro et al., 2012).
Very interestingly, the effect of the $\mathrm{CD} 146^{+}$cell (i.e., pericytes) subpopulation of the stromal fraction of human adipose tissue was investigated and compared with that of AT-MSCs from the same sample. Weekly intraperitoneal transplantations of $\mathrm{CD}_{146^{+}}$cells in the DMD mouse model were able to sustain muscle regeneration for up to 8 weeks after transplantation, and this effect was stronger when compared with that of AT-MSCs (Gomes et al., 2018).

The potential of human dental pulp stem cells (DP-MSCs) and of human amniotic fluid stem cells (AF-MSCs) was also assessed in an immune-compromised mdx/SCID model (Pisciotta et al., 2015). MSCs were pre-committed in vitro toward the myogenic lineage by means of a DNA demethylation treatment, in both the presence and absence of $\mathrm{CM}$ from differentiated $\mathrm{C} 2 \mathrm{C} 12$ cell cultures, that induced the expression of specific myogenic commitment markers (i.e., myogenin, myosin heavy chain, and desmin). Pre-differentiated DP-MSCs and AF-MSCs were then injected intramuscularly in mice, and both cell types were able to restore dystrophin expression and slow down muscle degeneration by exerting pro-angiogenic and anti-fibrotic effects (Pisciotta et al., 2015).

MSCs have also been tested in sarcoglycanopathies, another chronic muscular disorder (Shabbir et al., 2009). These diseases result from the absence of sarcoglycan proteins whose role is to connect the cytoskeleton of muscle fibers to the sarcolemma in order to maintain structural integrity of the myofibers (Gao et al., 2015). Indeed, Shabbir and colleagues demonstrated that intramuscular transplantation of human or pig BM-MSCs in delta-sarcoglycan-deficient dystrophic hamsters was able to significantly decrease CD45 and NFkB expression. In addition, MSC treatment was able to decrease malondialdehyde (MDA) expression, the final product of lipid peroxidation induced by inflammation that characterizes dystrophic muscles, similar to that of wild-type mice (Shabbir et al., 2009).

Based on these findings, the authors concluded that the immunomodulatory properties of MSCs can be exploited as a possible therapy for chronic inflammatory conditions such as muscular dystrophies (Shabbir et al., 2009).

Altogether, several studies have shown how MSCs derived from different sources, injected both locally and systemically, can also exert beneficial effects in severe forms of muscular dystrophies by acting at different levels to hamper muscle degeneration.

\section{Atrophic Muscle}

Muscular atrophy can be a physiological process due to aging or long-term immobilization, or it can be a consequence of pathogenic conditions such as spinal muscular atrophy (SMA) or other chronic diseases like muscular dystrophies, amyotrophic lateral sclerosis (ALS), cancer, acquired immunodeficiency syndrome (AIDS), and diabetes (Bonaldo and Sandri, 2013). Muscular atrophy is characterized by the loss of muscle mass due to myofiber death, change in fiber types and myosin isoforms, reduction of cell cytoplasm, loss of cellular organelles, and, in particular, protein degradation that exceeds the synthesis of new proteins. 
Kim and colleagues demonstrated how human MSCs isolated from different sources (bone marrow, adipose tissue, and umbilical cord) can induce muscle regeneration after transplantation into the soleus of rats with hindlimb suspensioninduced muscle atrophy (Kim et al., 2015). In particular, the authors observed activation of the phosphoinositide-3kinase (PI3K)/Akt pathway and consequently a reduction of muscle-specific RING finger protein-1 (MuRF-1) and atrophy F-box (MAFbx/Atrogin-1) expression in rats treated with MSCs (Kim et al., 2015).

ALS is a serious progressive neurodegenerative pathology characterized by the loss of motor neurons with consequent atrophy and loss of muscle movements (Hardiman et al., 2017). Numerous studies conducted in mice with the Gly93Ala mutation in the SOD1 gene (SOD1-G93A mice), which leads to the development of ALS symptoms (progressive loss of muscle strength, onset of the disease at about 5 months, and a life span of about 6 months) (Julien and Kriz, 2006), have demonstrated that BM-MSCs induce important therapeutic effects (Zhao et al., 2007; Vercelli et al., 2008; Zhou et al., 2013). Different works highlighted how BM-MSC transplantation in ALS mice improves disease phenotype, delays disease progression, and induces partial recovery of the motor function (Zhao et al., 2007; Vercelli et al., 2008; Gugliandolo et al., 2019).

In particular, it has been shown that intravenous injection of human BM-MSCs injected into SOD1-G93A mice was able to delay the development of pathology-related symptoms and to promote survival when compared with untreated and vehicle-injected mice (Zhao et al., 2007). Moreover, the functions of neuromotors were also analyzed, and again, significant differences were found. In particular, when compared with untreated mice, those that received human BM-MSCs lost motor function almost a month after treatment and had a higher number of motor neurons (Zhao et al., 2007). Furthermore, human BM-MSCs prevented the loss of peripheral motor nerves, and reinnervation took longer for treated mice.

Zhang and collaborators also demonstrated that multiple intrathecal injections of human BM-MSCs induced therapeutic effects in SOD1-G93A mice by enhancing motor performance, decreasing motor neuron loss, and increasing survival through the inhibition of the inflammatory response as shown by downregulation of TNF- $\alpha$ and iNOS protein levels (Zhang et al., 2009; Zhou et al., 2013).

Another study also demonstrated that when transplanted into the lumbar spinal cord of SOD1-G93A mice, BM-MSCs were able to migrate in the lumbar spinal cord, prevent microglial activation, and delay disease onset associated with a decrease in the number of motor neurons, thus globally leading to a better muscle performance (Vercelli et al., 2008).

The striking effectiveness of AT-MSCs for ALS has also been demonstrated. Systemic injection of AT-MSCs into the SOD-1 mutant mouse was able to modulate the secretome of local glial cells and increase glial-derived neurotrophic factor (GDNF) levels, which consequently led to neuroprotection and increased the number, survival, and functionality of motor neurons (Marconi et al., 2013).
Taken together, administration of MSCs, and especially of BM-MSCs, in ALS models is effective in decelerating disease symptoms as well as in sustaining muscle innervation, acting on both muscle and motor neuron sides.

\section{THE THERAPEUTIC POTENTIAL OF THE MESENCHYMAL STROMAL CELL SECRETOME}

In recent years, the regenerative potential of MSCs has not been attributed so much to the ability of these cells to engraft into target tissue and differentiate but to their ability to secrete factors capable of supporting tissue regeneration through activation of resident cells.

CM-MSCs have been shown to be a valid alternative to its cellular counterpart (MSCs) by numerous in vitro and in vivo studies, which describe similar beneficial effects between the two (Gnecchi et al., 2006; Aslam et al., 2009; Rossi et al., 2012; Goolaerts et al., 2014).

Different in vitro studies have shown that CM-MSC affects different immune cell populations of the innate (macrophages, dendritic cells, neutrophils, and natural killer cells) and adaptive (T and B cell) immunity. For example, CM-MSCs obtained from different tissues, such as bone marrow, adipose tissue, and muscle tissue, inhibit T-cell proliferation (Di Nicola et al., 2002; Keyser et al., 2007; Hegyi et al., 2012; Lang et al., 2018), support the expansion of T regulatory cells (Nasef et al., 2007; Yang et al., 2009; Sattler et al., 2011; Tasso et al., 2012), and inhibit B-cell proliferation (Augello et al., 2005; Corcione et al., 2006) and B-cell differentiation (Asari et al., 2009). Furthermore, CM-MSCs have been shown to induce a phenotype and functional switch of monocytes toward macrophages with anti-inflammatory, M2-like features (Onishi et al., 2015; Pischiutta et al., 2016; Magatti et al., 2017; Giampà et al., 2019), to inhibit natural killer cell proliferation and cytotoxicity (Rasmusson et al., 2003; Sotiropoulou et al., 2006), and to inhibit dendritic cell differentiation (Nauta et al., 2006; Djouad et al., 2007; Ramasamy et al., 2007; Li et al., 2008). Moreover, the administration of CMMSC has been shown to induce therapeutic effects in a wide variety of disease models, such as sepsis (Németh et al., 2009), and to support the repair of several tissues such as the liver (Zagoura et al., 2012), lungs (Ray et al., 2003; Cargnoni et al., 2012; Turner et al., 2013), skin (Lee et al., 2011), and heart (Mirabella et al., 2011) and moreover, it possesses neuroprotective and neurotrophic abilities (Mead et al., 2014; Caseiro et al., 2016; Giampà et al., 2019).

The advantages of using CM-MSCs lie in its composition of soluble factors and EVs. In particular, EVs are very attractive for a cell-free therapeutic approach in regenerative medicine since they bypass some undesirable side effects of MSCs, such as their ability to enhance tumor growth by chemokine or cytokine secretion (Liu et al., 2011; Tsai et al., 2011; Yan et al., 2012), and their inability to proliferate overcomes the tumorigenesis potential of MSCs (Rani et al., 2015; Mardpour et al., 2019).

The use of MSC-EVs as a therapeutic approach is advantageous also for other reasons: (i) the ability to migrate 
specifically into the target organ while MSCs often become entrapped in the microvasculature leading to a high risk of thrombosis (Gowen et al., 2020; Zhao et al., 2020); (ii) the systemic injection of EVs has an improved safety profile and lower immunogenicity with any histopathological changes or increases of liver transaminases or cytokine levels (Koniusz et al., 2016; Zhu et al., 2017; Leavitt et al., 2019; Saleh et al., 2019; Shiue et al., 2019); (iii) EVs are a putative delivery system of genes, drugs, enzymes, and RNAs, and they can be engineered to target specific cells or pathways (Yeo et al., 2013; Pascucci et al., 2014; Tian et al., 2018; Asgarpour et al., 2020; Conceição et al., 2021). All these characteristics make MSC-EVs promising tools for cell-free therapeutics.

\section{Therapeutic Effects of the Mesenchymal Stromal Cells Secretome in Muscle Regeneration}

As for other pathologies, it has been proven that when locally or systemically injected, MSCs activate muscle resident cells due to the release of paracrine factors, such as VEGFa, improving muscle regeneration and/or modulating muscle inflammation and muscle fibrosis (Pinheiro et al., 2012; Secco et al., 2013; Valadares et al., 2014).

In the context of skeletal muscle diseases, Assoni and colleagues demonstrated in vitro that CM from adipose tissue, skeletal muscle, and uterine tube MSCs has the ability to modulate apoptosis of dystrophic myoblasts, also enhancing cell migration and proliferation (Assoni et al., 2017). Through proteomic profiling of the $\mathrm{CM}$, they also demonstrated the great variability of proteins from the different sources analyzed but also highlighted common enriched pathways related to extracellular matrix organization, axon guidance, antigen processing, metabolic processes, and positive regulation of nitric oxide (Assoni et al., 2017).

Another study demonstrated that the transplantation of CMWJ-MSCs showed better results on inflammation and collagen deposition in muscle tissue than transplantation of the source cells (Pereira et al., 2014). These effects were due to the presence of cytokines and growth factors involved in the suppression of local immune system, such as hepatocyte growth factor (HGF) and IL-10, in the improvement of angiogenesis, such as fibroblast growth factor (FGF) and VEGFA, and in the inhibition of scar formation (Chen et al., 2008; Li et al., 2009; Jackson et al., 2012).

In a different study, Kim and collaborators showed that injection of human CM-UC-MSCs in a mouse model of muscle atrophy induced recovery of the muscle mass through the activation of PI3K/Akt pathway (Kim et al., 2016). In addition, using an antibody-based protein array, the authors characterized factors released by human umbilical cord-derived MSCs (UCMSCs) (Kim et al., 2016). Interestingly, several regulators of muscle regeneration were identified: ectodysplasin-A2, thrombospondin-1, IL-6, monocyte chemoattractant protein-1 (MCP-1), dickkopf-related protein 1 (DKK1), HGF, VEGF, FGF7, tissue inhibitor of metalloproteinase 1 (TIMP-1), SMAD family member 4 (SMAD4), macrophage inflammatory protein
2 (MIP-2), activin A, insulin-like growth factor-binding protein (IGFBP)-related protein 1, and MMP-1 (Kim et al., 2016).

These seminal works clearly demonstrate that the efficacy of MSCs in supporting skeletal muscle regeneration is attributed to secreted factors that exert a bioactive effect in damaged muscles.

\section{Therapeutic Effects of Extracellular Vesicles Derived From Mesenchymal Stromal Cells in Muscle Regeneration}

MSC-EV-derived therapeutic approaches have been exploited in several pathologies, such as liver diseases (Lou et al., 2015; Qu et al., 2017; Chen et al., 2018; Shao et al., 2020; Zhang et al., 2020), brain diseases including brain tumors (Xin et al., 2012, 2013; Xu et al., 2019; Allahverdi et al., 2020), cardiac dysfunctions, and myocardial infarction (Feng et al., 2014; Yu et al., 2015).

The therapeutic potential of MSC-EVs in supporting skeletal muscle regeneration in the context of muscle diseases has also been evaluated. Nakamura et al. (2015) described the in vitro beneficial effect of EVs isolated from BM-MSCs on myogenesis and angiogenesis of $\mathrm{C} 2 \mathrm{C} 12$ myoblasts and HUVECs, respectively. The authors confirmed these data in the CTX mouse model, in which they performed an intramuscular injection of MSCEVs and observed an increase of muscle cross-sectional area, a decrease of fibrotic area, and an improvement of capillary density (Nakamura et al., 2015). The interest toward MSCEVs as an efficacious treatment for degenerative neuromuscular diseases has also escalated due to the fact that EVs are lipid vesicles of endocytic origin that can cross the blood-brain barrier (BBB) in a non-invasive manner (Zhuang et al., 2011; Zhou et al., 2014). Several studies have reported that the beneficial effects are associated with EV cargo. In particular, a comparison of miR content in MSC-EVs and in CM-MSCs has revealed several miRs in common and others exclusive for MSC-EVs (Nakamura et al., 2015). For example, miR-21, an anti-apoptotic miR, was present in both the MSC-EVs and MSC$\mathrm{CM}$, but as already reported by others, miRs encapsulated in EVs appeared to have enhanced functions when compared with miRs released in the total CMs (Shimbo et al., 2014; Nakamura et al., 2015). The analysis of miRs cargo showed the presence of myogenic miRs, such as miR-1, miR-133, and miR-206, but also of miR-494, which has been shown to induce a protective effect against ischemia-induced cardiac injury (Wang et al., 2010; Nakamura et al., 2015). Lo Sicco and colleagues investigated the angiogenic effect of EVs isolated from AT-MSCs in a mouse model of muscle damage (Lo Sicco et al., 2017). They implanted matrigel plugs containing MSC-EVs in mice and observed that 3 weeks after the implantation, there was an increase of vessels along the periphery of the plugs (Lo Sicco et al., 2017). The described effect of MSC-EVs was associated with the high expression, in their cargo, of the angiogenic factors platelet and endothelial cell adhesion molecule (PECAM) and VEGFA (Lo Sicco et al., 2017). Moreover, EVs isolated from MSCs cultured in hypoxic conditions were able to upregulate the expression of several miRs implicated in muscle repair, in particular miR223, miR-146b, miR-126, and miR-199a (Lo Sicco et al., 2017). By in vitro and in vivo experiments, MSC-EVs, especially 
when isolated from MSCs cultured in hypoxic conditions, were able to modulate inflammation by regulating macrophage polarization and accelerating muscle regeneration (Lo Sicco et al., 2017). Concordantly, others described the beneficial effects of the secretome (the whole CM and EV fraction) of human AF-MSCs on muscle homeostasis, highlighting their anti-inflammatory activity, their ability to enhance proliferation, and their capacity to protect against cellular senescence in the CTX mouse model (Mellows et al., 2017). In particular, the beneficial effect observed was mediated, at least in part, through the repression of NF-KB pathway, which appears stronger in MSC-EVs compared with the whole CM. Interestingly, the pro-regenerative effect of MSC-EVs in CTX mice was also associated with their miR content, which was predicted to promote angiogenesis, proliferation, migration, differentiation, autophagy, apoptosis, and inflammation (Mellows et al., 2017). A comparison of the effects of the whole CM and EVs from AF-MSCs in the CTX mouse model revealed very few differences in muscle regeneration. CM-AF-MSCs increased regenerating fiber size, the number of capillaries/fibers, and the level of committed muscle stem cells, while AF-EVs increased the regenerating fiber size and the number of capillaries/fiber (Mellows et al., 2017).

On the other hand, the recent comparison of the whole secretome with the EV fraction with AT-MSCs showed differences in protein and miR expression leading to a different impact from secretome and/or EVs on biological processes. Several factors (both proteins and miRs) are described as potentially involved in different processes (Mitchell et al., 2019). For example, the whole secretome but not the EV fraction influenced senescence, while EVs but not the whole secretome impacted inflammation (Mitchell et al., 2019). Notably, Mitchell and colleagues highlighted the greater effect of EVs in muscle repair in acute damage conditions in CTX mice. Indeed, by studying the miR contents in MSC-EVs, they observed the presence of anti-inflammatory (i.e., miR-let7 family), proregenerative (i.e., miR-145), and angiogenic miRs (i.e., miR23a), all able to improve muscle regeneration in CTX mice (Mitchell et al., 2019).

Local injection of exosomes isolated from the CM of BMMSCs was very recently shown to accelerate the recovery of contractile function of muscles in a rat model of muscle injury (Iyer et al., 2020). Treatment stimulated the formation of new fibers and modulated the expression of genes involved in inflammation, fibrosis, and myogenesis mechanisms (Iyer et al., 2020). Furthermore, another study demonstrated that intramuscular injection of exosomes from BM-MSCs after muscle contusion in mice modified the polarization status of macrophages, alleviated the inflammatory reaction, reduced fibrosis size, promoted muscle regeneration, and improved fasttwitch and tetanus strength (Luo et al., 2020).

The therapeutic effects of placenta-derived MSCs (PL-MSCs) and their secreted $\mathrm{EV}$ exosomes were assessed in vitro in myoblasts isolated from DMD patients and mdx mice and in vivo by intramuscular transplantation of PL-MSCs in $\mathrm{mdx}$ mice (Bier et al., 2018). In particular, both PL-MSCs and their EVs promoted fusion and differentiation of human muscle cells from DMD patients, as well as decreased the expression of TGF$\beta$ and thus the fibrogenic differentiation of DMD myoblasts. MiR-29 was identified as a mediator of this effect since it has been associated with various pathological pathways in DMD, and it is downregulated in myoblasts from DMD patients compared with muscle cells from healthy donors (Bier et al., 2018). Intriguingly, both PL-MSCs and their EVs induced the dystrophin homolog utrophin in $\mathrm{C} 2 \mathrm{C} 12$ cells and in human myoblasts derived from healthy donors and DMD patients. Intramuscular transplantation of PL-MSCs and EVs in mdx mice showed comparable effects; in fact, both treatments inhibited fibrosis and inflammation (Bier et al., 2018). Also, local injections of EVs isolated from UC-MSCs or systemic administration of murine BM-MSC-EVs in $\mathrm{mdx}$ mice counteracted DMD pathology. Both treatments induced the recovery of muscle function, the decline of creatinine kinase (CK) blood levels, and the decrease of muscle fibrosis and inflammation due to the re-localization of the dystrophin-associated protein complex (DAPC) (Leng et al., 2020).

Our recent studies have also demonstrated how miR content of EVs derived from muscular interstitial MSCs, FAPs, could play a pivotal role in muscle regeneration (Sandonà et al., 2020). We demonstrated that EVs mediate the communication between FAPs and MuSCs in dystrophic mice; and additionally, we reported the first evidence of pharmacological treatment ability to fine-tune EV cargo, enhancing their regenerating effects on muscle fibers (Sandonà et al., 2020). The pharmacological treatment of $\mathrm{mdx}$ with an epigenetic drug, histone deacetylase (HDAC) inhibitor [HDACi; i.e., Trichostatin A (TSA)], induced a significant upregulation of $14 \mathrm{miRs}$ inside the EVs released by FAPs of dystrophic mice (miR-206, miR-542, miR-449a, miR-342, miR-320, miR-192, miR-423, miR-376a, miR-145a, miR-224, miR-30a, miR-494, miR-29a, and miR-7b), which are mainly involved in muscle regeneration and muscle homeostasis (Sandonà et al., 2020). Among them, miR-206 was found to be the most upregulated following HDACi treatment and was found to be crucial to confer the ability to drive muscle regeneration, and to reduce fibrotic tissue deposition and muscle inflammation, to EVs injected in dystrophic muscles. This was confirmed by antagomiR inhibition of miR-206 expression in EVs, which led to the loss of the ability of EVs to impact muscle regeneration and muscle fibrosis but did not affect muscle inflammation (Sandonà et al., 2020). In addition, the inhibition of the expression of miR-145a, another HDACi-induced miR in EVs, reduced inflammation in the muscles of $\mathrm{mdx}$ mice. Therefore, we concluded that the specific assembly of miRs inside the EVs is fundamental to reveal their therapeutic effect in DMD (Sandonà et al., 2020).

Interestingly, the therapeutic efficacy of MSCs secreted vesicles has also been recently demonstrated in muscle atrophy. In particular, EVs from human UC-MSC (hUC-MSC-EVs) injected in rats with sciatic nerve defects were capable of restoring hind leg muscle mass thanks to extensive muscle innervation (Ma et al., 2019). The hUC-MSC-EVs promoted the nerve regeneration by the modulation of the inflammation, as observed by the downregulation of IL- 6 and IL- $1 \beta$ and the up-regulation of $\mathrm{IL}-10$, improving functional recovery. 
There is also reported evidence that the increment of muscle mass in atrophic muscles could be restored by the injection of MSC-EVs in injured muscles of rat with massive rotator cuff tear (MRCT) (Wang et al., 2019). In this model, EVs inhibited macrophage migration and the release of pro-inflammatory cytokines, preventing secondary muscle damage; moreover, vesicles were able to reduce the apoptosis of tenocytes and myocytes and to increase myogenesis of endogenous stem cell residing in the muscle (Wang et al., 2019).

Therapeutic approaches with MSC-EVs have also been tested on other chronic pathologies such as ALS. There are new and promising therapeutic approaches for ALS using MSC-EVs, in particular those isolated from AT-MSCs. AT-MSCs possess neuroprotective properties mediated by their EVs. EVs derived from AT-MSCs and in particular exosomes could be used for therapeutic approaches for ALS because they are capable of acting on different hallmarks of the disease. Indeed, an in vitro study using the NSC-34 motorneuron cell line overexpressing hSOD1 has shown that AT-MSC-EVs prevented $\mathrm{H}_{2} \mathrm{O}_{2}$-induced damage and increased cell viability (Bonafede et al., 2016).

The subsequent proteomic analyses of AT-MSC-derived exosomes revealed that it contains proteins that affect pathways crucial for ALS pathology, such as cell adhesion, apoptosis, response to oxidative stress, and $\mathrm{PI} 3 \mathrm{~K} / \mathrm{Akt}$ signaling pathway (Bonafede et al., 2019). The neuroprotective effect of ATMSC-derived exosomes in ALS could be associated with the presence of the ribonuclease RNAse4, a protein mutated in ALS patient, which is known to display angiogenic, neurogenic, and neuroprotective activities (Li et al., 2013; Bonafede et al., 2019; Padhi and Gomes, 2019). With the use of an in vitro model of ALS, the transfer of SOD1 and SOD3 through exosomes destroyed free superoxide radicals generating a protective effect replacing the enzymatic function of mutated SOD1, thus improving response to oxidative stress. In addition, Igf1, which activates the PI3K/Akt signaling pathway and binds Igf1R promoting proliferation and inhibiting apoptosis, was also found inside AT-MSC-derived exosomes (Bonafede et al., 2019). Other in vitro studies on neural stem cells (NSCs) isolated from the SOD1-G93A ALS mouse model have demonstrated that treatment with AT-MSC-EVs could reduce the increase of SOD1 aggregation in the cytoplasm of cells (Lee et al., 2016). Moreover, EV treatment had also effects on mitochondrial defects: NSCs treated with AT-MSC-EVs showed an increase in mitochondrial protein expression, such as p-CREB/CREB and PGC1 $\alpha$ involved in the activation of mitochondrial biogenesis and have been reported to be abnormally expressed in ALS (Kong and Xu, 1998; Lee et al., 2016).

The recent available literature clearly suggests that the intravesicular portion of CM-MSCs has therapeutic implications for musculoskeletal diseases and, at the same time, assesses the feasibility of using EVs in treatment of diseases that have no cure to date.

The deep investigation of the identity of EV cargo in terms of proteins, mRNA, and miRNAs can be harnessed therapeutically in the more immediate future by engineering vesicles for specifically delivering therapeutic components to the target tissue.

\section{CLINICAL TRIALS IN HUMANS}

Thanks to their regenerative potential, MSCs have been tested in different clinical trials for cardiovascular, neurological, and immunological diseases, among others (Chen et al., 2004; Bang et al., 2005; Lazarus et al., 2005; Ringden et al., 2006; Ripa et al., 2007; Markert et al., 2009; Lee et al., 2012; Rajput et al., 2015; Pezzi et al., 2017; Kim et al., 2018; Winkler et al., 2018). Despite several advantages of using MSCs in clinical trials, most of them have failed to reach primary endpoints. The therapeutic ineffectiveness resides mostly on the age of the MSC donor, on the different MSC isolation and culture methods, on the various MSC administration routes, and on the MSC recipient (host) (Yukawa et al., 2012; Siegel et al., 2013; Stubbendorff et al., 2013; Pezzi et al., 2017).

For example, cell isolation methods can yield nonhomogenous cell populations that can consequently affect clinical outcome. In addition, long-term culture has been shown to decrease differentiation ability (Drela et al., 2019), increase malignant transformation of MSCs from BM (Røsland et al., 2009; Drela et al., 2019), and reduce engraftment in vivo (Bonab et al., 2006; Tolar et al., 2007; Yang et al., 2018).

Although several studies have shown the efficacy of both MSCs and their secretome in preclinical models of muscle diseases, there are very few clinical trials.

With the use of the key terms "muscle" and "mesenchymal cells" and selecting only studies concerning the use of MSCs in muscular diseases, eight clinical trials are registered on ClinicalTrial.gov ${ }^{1}$. Amongst these, six are in DMD patients, one in patients with facioscapulohumeral dystrophy (FSHD), and one in Werdnig-Hoffman patients. Four trials involved the use of umbilical cord MSCs, two used adipose-derived MSCs, and the remaining two used BM-MSCs. There are no results available for these eight selected studies on ClinicalTrial.gov ${ }^{1}$.

Twenty-two approved and registered clinical trials were found on www.clinicaltrials.gov using the search terms "ALS" and "mesenchymal cells"; and they also evaluated the efficacy of MSCs, isolated from different sources, in ALS patients. The results were recently reviewed in detail by Gugliandolo and colleagues (Gugliandolo et al., 2019).

Very interestingly, a phase 2 clinical trial (ClinicalTrials.gov Identifier: NCT03406780) investigated the safety and efficacy of a cell therapy called CAP-1002 in DMD patients. CAP1002 is a therapeutic product composed of allogenic cardiac progenitor cells, namely, cardiosphere-derived cells, and it has been previously demonstrated that intracoronary infusion of CAP-1002 is feasible, safe, and potentially effective in DMD patients (Taylor et al., 2019). These cardiospheres have been proposed to act through the secretion of different growth factors and exosomes exerting anti-inflammatory, anti-fibrotic, and regenerative actions in the target organ (Taylor et al., 2019).

In the last couple of years, different publications have reported clinical trials results. For example, the suitability, safety, and efficacy of intra-arterial and intramuscular administration of allogeneic WJ-MSCs in ambulatory and non-ambulatory DMD

\footnotetext{
${ }^{1}$ https://www.clinicaltrials.gov/
} 


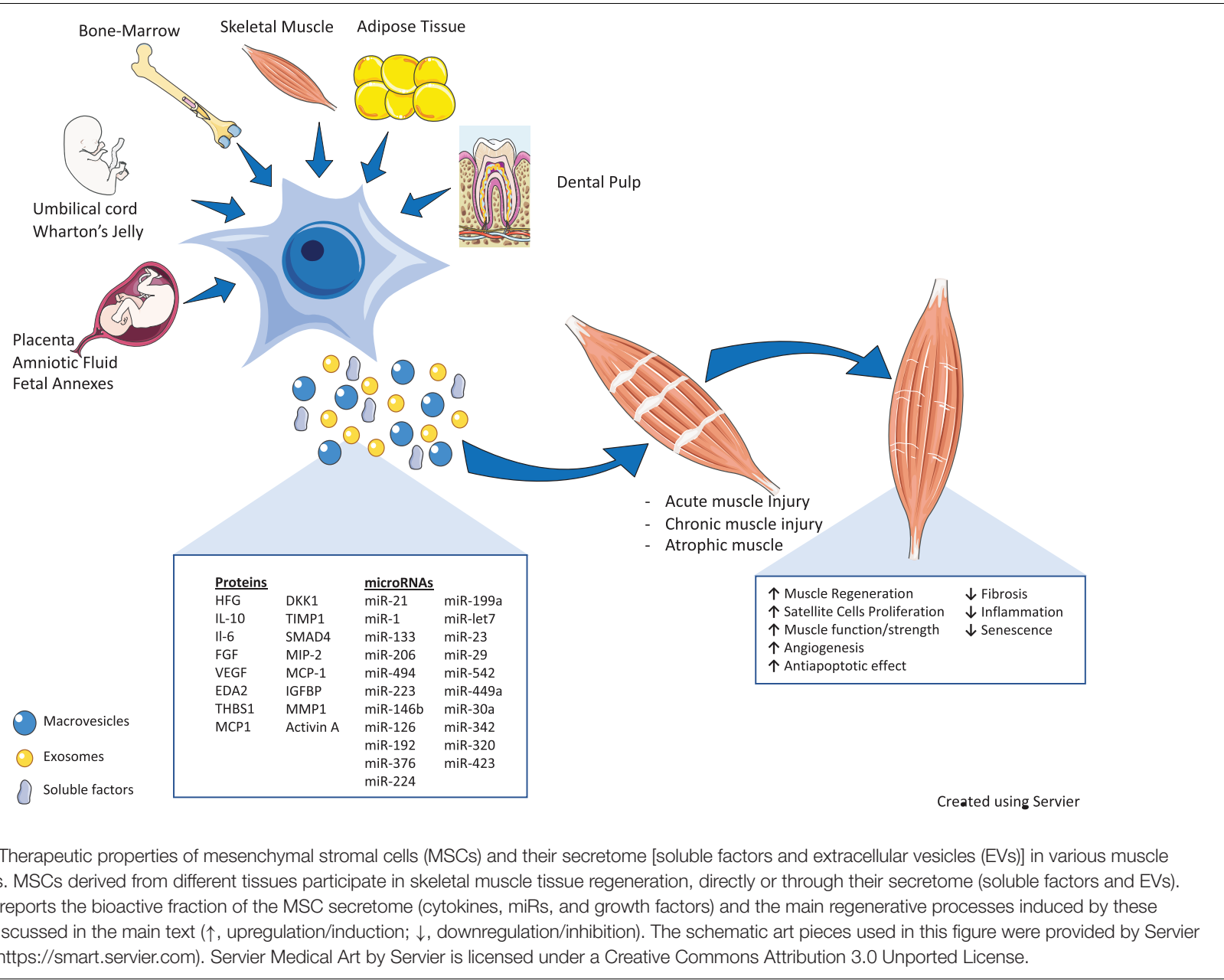

patients were found be well tolerated, ameliorated symptoms, and slowed the progression of the disease in the first year following the administration (Dai et al., 2018). Furthermore, the feasibility of treatment with BM-MSCs in patients with DMD (Sharma et al., 2014; Klimczak et al., 2020) and with ALS (Nabavi et al., 2019) has been also evaluated. In particular, intravenous and intrathecal injections of autologous BM-MSCs in ALS patients were found to be safe and feasible (Nabavi et al., 2019). Klimczak and colleagues tested the effects of the intramuscular co-transplantation of BMMSCs and myogenic progenitor cells in three DMD patients, based on the rationale that both cell types can merge with damaged myofibers to regenerate skeletal muscle and from the knowledge that BM-MSCs are involved in myogenesis due to their ability to differentiate into myoblasts and to inhibit chronic inflammation that characterizes DMD (Klimczak and Kozlowska, 2016; Klimczak et al., 2018). They demonstrated that BM-MSCs had immunomodulatory properties that supported the regenerative potential of the myogenic precursors in vivo (Klimczak et al., 2020).

Finally, intravenous administration of UC-MSCs in patients affected by Becker muscular dystrophy was found to be safe and determined an increase of muscle strength, a result that is interestingly more evident in patients with a shorter course of disease (Li et al., 2015).

\section{CONCLUSION}

The incredible and multifaceted properties of MSCs have attracted great scientific interest for the possible development of numerous therapeutic applications, making them the most commonly used cells, especially in the regenerative medicine field. They can be obtained from many different adult tissues and, for the most part, are easy to isolate and culture. When tissues are damaged, administrated MSCs have the ability to migrate to the site of injury and to release molecules (growth factors, cytokines, and EVs) that establish a favorable microenvironment and promote tissue homeostasis that supports or directly favors regeneration by the induction of pleiotropic effects: anti-inflammatory, immune-modulating, anti-fibrotic, angiogenic, and anti-apoptotic (Chapel et al., 2003; Caplan, 2009; Singer and Caplan, 2011; Le Blanc and Mougiakakos, 2012; Bronckaers et al., 2014).

In this review, we have emphasized the current knowledge about MSCs and how MSCs derived from different origins are widely used in the treatment of various diseases with a particular focus on muscular diseases. In the last decade, we have learned that MSCs act through paracrine factors, and in particular through the EVs they release. For all these reasons, we have provided insights into the possible therapeutic employment of the 
MSCs with a special attention to their secretome and EVs as novel off-the-shelf approaches for muscle regeneration.

Although different studies described the ability of MSCs to target specific damaged tissues, long-term engraftment is not often observed (Toma et al., 2002), and several alternative mechanisms have changed the "cell replacement theory" behind the beneficial effect of MSCs of promoting tissue repair.

Numerous recent preclinical and clinical studies here discussed demonstrated that the therapeutic effect of MSCs secretome in skeletal muscle regeneration could be partly due to secreted EVs, which can mirror the therapeutic effect of their parent cells. We have discussed in detail how EVs released by MSCs are able to mediate intercellular communication that is translated into pleiotropic actions generating therapeutic potential through the transfer of active molecules, also in different muscle injury models (Figure 1).

The use of MSC-CM and in particular of MSC-derived EVs as a cell-free therapy is quickly developing as a promising option that could bypass the safety concerns associated with the use of live cells, ethical concerns associated with the origin of cells, and also immune-compatibility issues.

The MSC secretome is considered a potential bioactive pharmaceutical component, in which its vesicular portion, containing genetic information transmitted between cells of different types, is promising as a drug delivery system mainly due to homing capabilities, thereby opening an opportune window to specific and targeted compound (drugs, proteins, etc.) release into damaged lesions (Bari et al., 2018). A secretome-based approach should also minimize biological variability, allow precise dosing, and thus lead to the development of safe and effective therapeutic strategies with possibly predictable outcomes.

EVs isolated from MSCs constitute the best alternative to cellfree therapy due to low immunogenicity, high biocompatibility, and low cytotoxicity to tissues. They can also be used for nanoregenerative medicine since they can be engineered to target specific cells or tissues and can work as drug carriers.

We and others demonstrated the beneficial effects and efficacious employment of EVs in reducing muscle injury effects and enhancing tissue repair (Ma et al., 2019; Wang et al., 2019; Sandonà et al., 2020; Figure 1). The alteration in the content of these vesicles leads to a miscommunication between cells in the diseased muscles (i.e., dystrophic muscles) and alters their behavior. This study showed the ability of MSC-EVs to transfer the benefits of drugs without causing the unwanted systemic side effects of these treatments, bringing new hope to regenerative medicine for DMD (Sandonà et al., 2020).

Although there is a large body of evidence that has demonstrated the regenerative capacity of MSCs and their

\section{REFERENCES}

Allahverdi, A., Arefian, E., Soleimani, M., Ai, J., Nahanmoghaddam, N., Yousefi-Ahmadipour, A., et al. (2020). MicroRNA-4731-5p delivered by $\mathrm{AD}$-mesenchymal stem cells induces cell cycle arrest and apoptosis in glioblastoma. J. Cell. Physiol. 235, 8167-8175. doi: 10.1002/jcp. 29472 secretome in disease models of acute injury, chronic damage, and atrophy of the skeletal muscle, to date, little clinical evidence is reported in patients and is anyhow limited to the use of MSCs.

Unfortunately, clinical applications of EVs remain challenging due to lack of standardized protocols to produce vesicles for therapeutic use. There are open debates in the EV community (ISEV) about the diversity and preparation of MSCs and consequently about the methods of EV isolation and purification. These points, together with the lack of standardized quality assurance assays, and limited accuracy of in vitro and in vivo functional assays can affect the reproducibility of research results. In addition to these obstacles, low yield (Shao et al., 2018) and heterogeneity (Pegtel and Gould, 2019) need to be urgently addressed (Ayers et al., 2019).

A full understanding of the potential and efficacy of MSCs, and especially of their products, to support muscle regeneration will be a breakthrough for regenerative medicine that will identify new molecules for the repair and regeneration of skeletal muscle tissue.

\section{AUTHOR CONTRIBUTIONS}

MS, LDP, FE, AV, and VS: writing-original draft preparation. ARS, MS, LDP, OP, and VS: writing-review and editing. OP and VS: supervision. All authors final approval of the manuscript.

\section{FUNDING}

This work has been supported by the following funding: Association Francaise contre les Myopathies (AFM no. 21657) and Italian Ministry of Health (GR-2016-02362451) to VS; Italian Ministry of Research and University, PRIN 2017 (MIUR, grant no. 2017RSAFK7) to OP; $5 \times 1000$ year 2018; and Fondazione Poliambulanza.

\section{ACKNOWLEDGMENTS}

We thank Università Cattolica del Sacro Cuore, Rome, and Fondazione Santa Lucia, Rome. We would like to acknowledge the Regenerative Medicine Research Center (CROME) of Università Cattolica del Sacro Cuore. This work contributes to the COST Action CA17116 International Network for Translating Research on Perinatal Derivatives into Therapeutic Approaches (SPRINT) and supported by COST (European Cooperation in Science and Technology).

Andaloussi, E. L. S., Mäger, I., Breakefield, X. O., and Wood, M. J. A. (2013). Extracellular vesicles: biology and emerging therapeutic opportunities. Nat. Rev. Drug Discov. 12, 347-357. doi: 10.1038/nrd3978

Andrade, B. M., Baldanza, M. R., Ribeiro, K. C., Porto, A., Peçanha, R., Fortes, F. S. A., et al. (2015). Bone marrow mesenchymal cells improve muscle function in a skeletal muscle re-injury model. PLoS One 10:e127561. doi: 10.1371/ journal.pone.0127561 
Asari, S., Itakura, S., Ferreri, K., Liu, C.-P., Kuroda, Y., Kandeel, F., et al. (2009). Mesenchymal stem cells suppress B-cell terminal differentiation. Exp. Hematol. 37, 604-615. doi: 10.1016/j.exphem.2009.01.005

Asgarpour, K., Shojaei, Z., Amiri, F., Ai, J., Mahjoubin-Tehran, M., Ghasemi, F., et al. (2020). Exosomal microRNAs derived from mesenchymal stem cells: cell-to-cell messages. Cell Commun. Signal. 18:149. doi: 10.1186/s12964-020-00 650-6

Aslam, M., Baveja, R., Liang, O. D., Fernandez-Gonzalez, A., Lee, C., Mitsialis, S. A., et al. (2009). Bone marrow stromal cells attenuate lung injury in a murine model of neonatal chronic lung disease. Am. J. Respir. Crit. Care Med. 180, 1122-1130. doi: $10.1164 / \mathrm{rccm} .200902-0242 \mathrm{OC}$

Assoni, A., Coatti, G., Valadares, M. C., Beccari, M., Gomes, J., Pelatti, M., et al. (2017). Different donors mesenchymal stromal cells secretomes reveal heterogeneous profile of relevance for therapeutic use. Stem Cells Dev. 26, 206-214. doi: 10.1089/scd.2016.0218

Augello, A., Tasso, R., Negrini, S. M., Amateis, A., Indiveri, F., Cancedda, R., et al. (2005). Bone marrow mesenchymal progenitor cells inhibit lymphocyte proliferation by activation of the programmed death 1 pathway. Eur. J. Immunol. 35, 1482-1490. doi: 10.1002/eji.200425405

Ayers, L., Pink, R., Carter, D. R. F., and Nieuwland, R. (2019). Clinical requirements for extracellular vesicle assays. J. Extracell. Ves. 8:1593755. doi: 10.1080/ 20013078.2019.1593755

Bang, O. Y., Lee, J. S., Lee, P. H., and Lee, G. (2005). Autologous mesenchymal stem cell transplantation in stroke patients. Ann. Neurol. 57, 874-882. doi: 10.1002/ana.20501

Bari, E., Perteghella, S., Di Silvestre, D., Sorlini, M., Catenacci, L., Sorrenti, M., et al. (2018). Pilot Production of mesenchymal Stem/stromal freeze-dried secretome for cell-free regenerative nanomedicine: a validated GMP-compliant process. Cells 7:190. doi: 10.3390/cells7110190

Bier, A., Berenstein, P., Kronfeld, N., Morgoulis, D., Ziv-Av, A., Goldstein, H., et al. (2018). Placenta-derived mesenchymal stromal cells and their exosomes exert therapeutic effects in Duchenne muscular dystrophy. Biomaterials 174, 67-78. doi: $10.1016 /$ j.biomaterials.2018.04.055

Bonab, M. M., Alimoghaddam, K., Talebian, F., Ghaffari, S. H., Ghavamzadeh, A., and Nikbin, B. (2006). Aging of mesenchymal stem cell in vitro. BMC Cell Biol. 7:14. doi: $10.1186 / 1471-2121-7-14$

Bonafede, R., Brandi, J., Manfredi, M., Scambi, I., Schiaffino, L., Merigo, F., et al. (2019). The anti-apoptotic effect of ASC-exosomes in an in vitro ALS model and their proteomic analysis. Cells 8:1087. doi: 10.3390/cells8091087

Bonafede, R., Scambi, I., Peroni, D., Potrich, V., Boschi, F., Benati, D., et al. (2016). Exosome derived from murine adipose-derived stromal cells: neuroprotective effect on in vitro model of amyotrophic lateral sclerosis. Exp. Cell Res. 340, 150-158. doi: 10.1016/j.yexcr.2015.12.009

Bonaldo, P., and Sandri, M. (2013). Cellular and molecular mechanisms of muscle atrophy. Dis. Model. Mech. 6, 25-39. doi: 10.1242/dmm.010389

Borges, F. T., Reis, L. A., Schor, N., Borges, F. T., Reis, L. A., and Schor, N. (2013). Extracellular vesicles: structure, function, and potential clinical uses in renal diseases. Braz. J. Med. Biol. Res. 46, 824-830. doi: 10.1590/1414-431X20132964

Bronckaers, A., Hilkens, P., Martens, W., Gervois, P., Ratajczak, J., Struys, T., et al. (2014). Mesenchymal stem/stromal cells as a pharmacological and therapeutic approach to accelerate angiogenesis. Pharmacol. Ther. 143, 181-196. doi: 10. 1016/j.pharmthera.2014.02.013

Campagnoli, C., Roberts, I. A., Kumar, S., Bennett, P. R., Bellantuono, I., and Fisk, N. M. (2001). Identification of mesenchymal stem/progenitor cells in human first-trimester fetal blood, liver, and bone marrow. Blood 98, 2396-2402. doi: 10.1182/blood.v98.8.2396

Cantaluppi, V., Gatti, S., Medica, D., Figliolini, F., Bruno, S., Deregibus, M. C., et al. (2012). Microvesicles derived from endothelial progenitor cells protect the kidney from ischemia-reperfusion injury by microRNA-dependent reprogramming of resident renal cells. Kidney Int. 82, 412-427. doi: 10.1038/ki. 2012.105

Caplan, A. I. (2009). Why are MSCs therapeutic? New data: new insight. J. Pathol. 217, 318-324. doi: 10.1002/path.2469

Cargnoni, A., Ressel, L., Rossi, D., Poli, A., Arienti, D., Lombardi, G., et al. (2012). Conditioned medium from amniotic mesenchymal tissue cells reduces progression of bleomycin-induced lung fibrosis. Cytotherapy 14, 153-161. doi: 10.3109/14653249.2011.613930
Caseiro, A. R., Pereira, T., Ivanova, G., Luís, A. L., and Maurício, A. C. (2016). Neuromuscular regeneration: perspective on the application of Mesenchymal stem cells and their secretion products. Stem Cells Int. 2016, e9756973. doi: 10.1155/2016/9756973

Chapel, A., Bertho, J. M., Bensidhoum, M., Fouillard, L., Young, R. G., Frick, J., et al. (2003). Mesenchymal stem cells home to injured tissues when coinfused with hematopoietic cells to treat a radiation-induced multi-organ failure syndrome. J. Gene Med. 5, 1028-1038. doi: 10.1002/jgm.452

Chen, C., Yang, Q., Wang, D., Luo, F., Liu, X., Xue, J., et al. (2018). MicroRNA191, regulated by HIF-2 $\alpha$, is involved in EMT and acquisition of a stem cell-like phenotype in arsenite-transformed human liver epithelial cells. Toxicol. Vitro Int. J. Publ. Assoc. BIBRA 48, 128-136. doi: 10.1016/j.tiv.2017.12.016

Chen, L., Tredget, E. E., Wu, P. Y. G., and Wu, Y. (2008). Paracrine factors of mesenchymal stem cells recruit macrophages and endothelial lineage cells and enhance wound healing. PLoS One 3:e1886. doi: 10.1371/journal.pone.00 01886

Chen, S., Fang, W., Ye, F., Liu, Y.-H., Qian, J., Shan, S., et al. (2004). Effect on left ventricular function of intracoronary transplantation of autologous bone marrow mesenchymal stem cell in patients with acute myocardial infarction. Am. J. Cardiol. 94, 92-95. doi: 10.1016/j.amjcard.2004.03.034

Chiu, C.-H., Chang, T.-H., Chang, S.-S., Chang, G.-J., Chen, A. C.-Y., Cheng, C.-Y., et al. (2020). Application of bone marrow-derived mesenchymal stem cells for muscle healing after contusion injury in mice. Am. J. Sports Med. 48, 1226-1235. doi: 10.1177/0363546520905853

Choi, A., Park, S. E., Jeong, J. B., Choi, S., Oh, S., Ryu, G. H., et al. (2020). Antifibrotic effect of human Wharton's Jelly-derived mesenchymal stem cells on skeletal muscle cells, mediated by secretion of MMP-1. Int. J. Mol. Sci. 21:6269. doi: $10.3390 /$ ijms 21176269

Conceição, M., Forcina, L., Wiklander, O. P. B., Gupta, D., Nordin, J. Z., Vrellaku, B., et al. (2021). Engineered extracellular vesicle decoy receptor-mediated modulation of the IL6 trans-signalling pathway in muscle. Biomaterials 266:120435. doi: 10.1016/j.biomaterials.2020.120435

Corcione, A., Benvenuto, F., Ferretti, E., Giunti, D., Cappiello, V., Cazzanti, F., et al. (2006). Human mesenchymal stem cells modulate B-cell functions. Blood 107, 367-372. doi: 10.1182/blood-2005-07-2657

Dai, A., Baspinar, O., Yeşilyurt, A., Sun, E., Aydemir, ÇÝ, Öztel, O. N., et al. (2018). Efficacy of stem cell therapy in ambulatory and nonambulatory children with Duchenne muscular dystrophy - Phase I-II. Degener. Neurol. Neuromuscul. Dis. 8, 63-77. doi: 10.2147/DNND.S170087

De Bari, C., Dell'Accio, F., Tylzanowski, P., and Luyten, F. P. (2001). Multipotent mesenchymal stem cells from adult human synovial membrane. Arthrit. Rheum. 44, 1928-1942. doi: 10.1002/1529-0131(200108)44:8<1928: AID-ART331<3.0.CO;2-P

De La Garza-Rodea, A. S., Van Der Velde-Van Dijke, I., Boersma, H., Gonçalves, M. A. F. V., Van Bekkum, D. W., De Vries, A. A. F., et al. (2012). Myogenic properties of human Mesenchymal stem cells derived from three different sources. Cell Transplant. 21, 153-173. doi: 10.3727/096368911X580554

Di Nicola, M., Carlo-Stella, C., Magni, M., Milanesi, M., Longoni, P. D., Matteucci, P., et al. (2002). Human bone marrow stromal cells suppress T-lymphocyte proliferation induced by cellular or nonspecific mitogenic stimuli. Blood 99, 3838-3843. doi: 10.1182/blood.v99.10.3838

Di Pietro, L., Barba, M., Prampolini, C., Ceccariglia, S., Frassanito, P., Vita, A., et al. (2020). GLI1 and AXIN2 are distinctive markers of human Calvarial Mesenchymal stromal cells in nonsyndromic craniosynostosis. Int. J. Mol. Sci. 21:4356. doi: 10.3390/ijms21124356

Djouad, F., Charbonnier, L.-M., Bouffi, C., Louis-Plence, P., Bony, C., Apparailly, F., et al. (2007). Mesenchymal stem cells inhibit the differentiation of dendritic cells through an interleukin-6-dependent mechanism. Stem Cells 25, 20252032. doi: 10.1634/stemcells.2006-0548

Dominici, M., Le Blanc, K., Mueller, I., Slaper-Cortenbach, I., Marini, F., Krause, D., et al. (2006). Minimal criteria for defining multipotent mesenchymal stromal cells. The international society for cellular therapy position statement. Cytotherapy 8, 315-317. doi: 10.1080/14653240600855905

Drela, K., Stanaszek, L., Nowakowski, A., Kuczynska, Z., and Lukomska, B. (2019). Experimental strategies of mesenchymal stem cell propagation: adverse events and potential risk of functional changes. Stem Cells Int. 2019, 7012692. doi: $10.1155 / 2019 / 7012692$ 
Eleuteri, S., and Fierabracci, A. (2019). Insights into the secretome of mesenchymal stem cells and its potential applications. Int. J. Mol. Sci. 20:4597. doi: 10.3390/ ijms20184597

Feng, Y., Huang, W., Wani, M., Yu, X., and Ashraf, M. (2014). Ischemic preconditioning potentiates the protective effect of stem cells through secretion of Exosomes by targeting Mecp2 via miR-22. PLoS One 9:e88685. doi: 10.1371/ journal.pone.0088685

Forterre, A., Jalabert, A., Berger, E., Baudet, M., Chikh, K., Errazuriz, E., et al. (2014). Proteomic analysis of C2C12 Myoblast and Myotube Exosome-like vesicles: a new paradigm for Myoblast-Myotube cross talk? PLoS One 9:e84153. doi: 10.1371/journal.pone.0084153

Friedenstein, A. J., Chailakhyan, R. K., Latsinik, N. V., Panasyuk, A. F., and Keiliss-Borok, I. V. (1974). Stromal cells responsible for transferring the microenvironment of the hemopoietic tissues. Cloning in vitro and retransplantation in vivo. Transplantation 17, 331-340. doi: 10.1097/00007890197404000-00001

Galderisi, U., and Giordano, A. (2014). The gap between the physiological and therapeutic roles of mesenchymal stem cells. Med. Res. Rev. 34, 1100-1126. doi: $10.1002 /$ med. 21322

Gao, Q. Q., Wyatt, E., Goldstein, J. A., LoPresti, P., Castillo, L. M., Gazda, A., et al. (2015). Reengineering a transmembrane protein to treat muscular dystrophy using exon skipping. J. Clin. Invest. 125, 4186-4195. doi: 10.1172/JCI 82768

Giampà, C., Alvino, A., Magatti, M., Silini, A. R., Cardinale, A., Paldino, E., et al. (2019). Conditioned medium from amniotic cells protects striatal degeneration and ameliorates motor deficits in the R6/2 mouse model of Huntington's disease. J. Cell. Mol. Med. 23, 1581-1592. doi: 10.1111/jcmm.14113

Gnecchi, M., He, H., Noiseux, N., Liang, O. D., Zhang, L., Morello, F., et al. (2006). Evidence supporting paracrine hypothesis for Akt-modified mesenchymal stem cell-mediated cardiac protection and functional improvement. FASEB J. 20, 661-669. doi: 10.1096/fj.05-5211com

Gomes, J. P., Coatti, G. C., Valadares, M. C., Assoni, A. F., Pelatti, M. V., Secco, M., et al. (2018). Human Adipose-Derived CD146+ stem cells increase life span of a muscular dystrophy mouse model more efficiently than Mesenchymal stromal cells. DNA Cell Biol. 37, 798-804. doi: 10.1089/dna.2018.4158

Goolaerts, A., Pellan-Randrianarison, N., Larghero, J., Vanneaux, V., Uzunhan, Y., Gille, T., et al. (2014). Conditioned media from mesenchymal stromal cells restore sodium transport and preserve epithelial permeability in an in vitro model of acute alveolar injury. Am. J. Physiol. Lung Cell. Mol. Physiol. 306, L975-L985. doi: 10.1152/ajplung.00242.2013

Gowen, A., Shahjin, F., Chand, S., Odegaard, K. E., and Yelamanchili, S. V. (2020). Mesenchymal stem cell-derived extracellular vesicles: challenges in clinical applications. Front. Cell Dev. Biol. 8:149. doi: 10.3389/fcell.2020.00149

Guescini, M., Guidolin, D., Vallorani, L., Casadei, L., Gioacchini, A. M., Tibollo, P., et al. (2010). C2C12 myoblasts release micro-vesicles containing mtDNA and proteins involved in signal transduction. Exp. Cell Res. 316, 1977-1984. doi: 10.1016/j.yexcr.2010.04.006

Gugliandolo, A., Bramanti, P., and Mazzon, E. (2019). Mesenchymal stem cells: a potential therapeutic approach for amyotrophic lateral sclerosis? Stem Cells Int. 2019:e3675627. doi: 10.1155/2019/3675627

Hardiman, O., Al-Chalabi, A., Chio, A., Corr, E. M., Logroscino, G., Robberecht, W., et al. (2017). Amyotrophic lateral sclerosis. Nat. Rev. Dis. Primer. 3, 1-19. doi: $10.1038 /$ nrdp. 2017.71

Hegyi, B., Kudlik, G., Monostori, É, and Uher, F. (2012). Activated T-cells and pro-inflammatory cytokines differentially regulate prostaglandin E2 secretion by mesenchymal stem cells. Biochem. Biophys. Res. Commun. 419, 215-220. doi: 10.1016/j.bbrc.2012.01.150

Helal, M. A. M., Shaheen, N. E. M., and Abu Zahra, F. A. (2016). Immunomodulatory capacity of the local mesenchymal stem cells transplantation after severe skeletal muscle injury in female rats. Immunopharmacol. Immunotoxicol. 38, 414-422. doi: 10.1080/08923973. 2016.1222617

Iraci, N., Leonardi, T., Gessler, F., Vega, B., and Pluchino, S. (2016). Focus on extracellular vesicles: physiological role and signalling properties of Extracellular membrane vesicles. Int. J. Mol. Sci. 17:171. doi: 10.3390/ ijms 17020171

Iyer, S. R., Scheiber, A. L., Yarowsky, P., Henn, R. F., Otsuru, S., and Lovering, R. M. (2020). Exosomes isolated from platelet-rich plasma and mesenchymal stem cells promote recovery of function after muscle injury. Am. J. Sports Med. 48, 2277-2286. doi: 10.1177/0363546520926462

Izadpanah, R., Trygg, C., Patel, B., Kriedt, C., Dufour, J., Gimble, J. M., et al. (2006). Biologic properties of mesenchymal stem cells derived from bone marrow and adipose tissue. J. Cell. Biochem. 99, 1285-1297. doi: 10.1002/jcb.20904

Jackson, W. M., Nesti, L. J., and Tuan, R. S. (2012). Mesenchymal stem cell therapy for attenuation of scar formation during wound healing. Stem Cell Res. Ther. 3:20. doi: $10.1186 /$ scrt111

Julien, J.-P., and Kriz, J. (2006). Transgenic mouse models of amyotrophic lateral sclerosis. Biochim. Biophys. Acta BBA Mol. Basis Dis. 1762, 1013-1024. doi: 10.1016/j.bbadis.2006.03.006

Kahroba, H., Hejazi, M. S., and Samadi, N. (2019). Exosomes: from carcinogenesis and metastasis to diagnosis and treatment of gastric cancer. Cell. Mol. Life Sci. 76, 1747-1758. doi: 10.1007/s00018-019-03035-2

Keyser, K. A., Beagles, K. E., and Kiem, H.-P. (2007). Comparison of Mesenchymal stem cells from different tissues to suppress T-Cell activation. Cell Transplant. 16, 555-562. doi: 10.3727/000000007783464939

Kharraz, Y., Guerra, J., Mann, C. J., Serrano, A. L., and Muñoz-Cánoves, P. (2013). Macrophage plasticity and the role of inflammation in skeletal muscle repair. Med. Inflamm. 2013:491497. doi: 10.1155/2013/491497

Kim, M. J., Kim, Y., Kim, Z.-H., and Heo, S.-H. (2015). Mesenchymal stem cells suppress muscle atrophy induced by Hindlimb suspension. Stem Cell Res. Ther. 5, 1-9.

Kim, M. J., Kim, Z.-H., Kim, S.-M., and Choi, Y.-S. (2016). Conditioned medium derived from umbilical cord mesenchymal stem cells regenerates atrophied muscles. Tissue Cell 48, 533-543. doi: 10.1016/j.tice.2016.06.010

Kim, S. H., Cho, J. H., Lee, Y. H., Lee, J. H., Kim, S. S., Kim, M. Y., et al. (2018). Improvement in left ventricular function with intracoronary Mesenchymal stem cell therapy in a patient with anterior wall st-segment elevation myocardial infarction. Cardiovasc. Drugs Ther. 32, 329-338. doi: 10.1007/s10557-0186804-Z

Kisiel, A. H., McDuffee, L. A., Masaoud, E., Bailey, T. R., Esparza Gonzalez, B. P., and Nino-Fong, R. (2012). Isolation, characterization, and in vitro proliferation of canine mesenchymal stem cells derived from bone marrow, adipose tissue, muscle, and periosteum. Am. J. Vet. Res. 73, 1305-1317. doi: 10.2460/ajvr.73.8. 1305

Klimczak, A., and Kozlowska, U. (2016). Mesenchymal stromal cells and tissuespecific progenitor cells: their role in tissue homeostasis. Stem Cells Int. 2016, 4285215. doi: 10.1155/2016/4285215

Klimczak, A., Kozlowska, U., and Kurpisz, M. (2018). Muscle Stem/progenitor cells and Mesenchymal stem cells of bone marrow origin for skeletal muscle regeneration in muscular dystrophies. Arch. Immunol. Ther. Exp. 66, 341-354. doi: 10.1007/s00005-018-0509-7

Klimczak, A., Zimna, A., Malcher, A., Kozlowska, U., Futoma, K., Czarnota, J., et al. (2020). Co-Transplantation of bone marrow-MSCs and Myogenic Stem/progenitor cells from adult donors improves muscle function of patients with Duchenne muscular dystrophy. Cells 9:1119. doi: 10.3390/cells9051119

Kong, J., and Xu, Z. (1998). Massive mitochondrial degeneration in motor neurons triggers the onset of amyotrophic lateral sclerosis in mice expressing a mutant SOD1. J. Neurosci. Off. J. Soc. Neurosci. 18, 3241-3250. doi: 10.1523/jneurosci. 18-09-03241.1998

Koniusz, S., Andrzejewska, A., Muraca, M., Srivastava, A. K., Janowski, M., and Lukomska, B. (2016). Extracellular vesicles in physiology, pathology, and therapy of the immune and central nervous system, with focus on extracellular vesicles derived from mesenchymal stem cells as therapeutic tools. Front. Cell. Neurosci. 10:109. doi: 10.3389/fncel.2016.00109

Kwon, S., Ki, S. M., Park, S. E., Kim, M.-J., Hyung, B., Lee, N. K., et al. (2016). Antiapoptotic effects of human Wharton's jelly-derived mesenchymal stem cells on skeletal muscle cells mediated via secretion of XCL1. Mol. Ther. J. Am. Soc. Gene Ther. 24, 1550-1560. doi: 10.1038/mt.2016.125

Lang, F. M., Hossain, A., Gumin, J., Momin, E. N., Shimizu, Y., Ledbetter, D., et al. (2018). Mesenchymal stem cells as natural biofactories for exosomes carrying miR-124a in the treatment of gliomas. Neuro Oncol. 20, 380-390. doi: 10.1093/neuonc/nox152

Lattanzi, W., Barba, M., Novegno, F., Massimi, L., Tesori, V., Tamburrini, G., et al. (2013). Lim mineralization protein is involved in the premature calvarial ossification in sporadic Craniosynostoses. Bone 52, 474-484. doi: 10.1016/j. bone.2012.09.004 
Lazarus, H. M., Koc, O. N., Devine, S. M., Curtin, P., Maziarz, R. T., Holland, H. K., et al. (2005). Cotransplantation of HLA-identical sibling cultureexpanded mesenchymal stem cells and hematopoietic stem cells in hematologic malignancy patients. Biol. Blood Marrow Transplant. 11, 389-398. doi: 10.1016/ j.bbmt.2005.02.001

Le Blanc, K., and Mougiakakos, D. (2012). Multipotent mesenchymal stromal cells and the innate immune system. Nat. Rev. Immunol. 12, 383-396. doi: 10.1038/ nri3209

Leavitt, R. J., Limoli, C. L., and Baulch, J. E. (2019). miRNA-based therapeutic potential of stem cell-derived extracellular vesicles: a safe cell-free treatment to ameliorate radiation-induced brain injury. Int. J. Radiat. Biol. 95, 427-435. doi: 10.1080/09553002.2018.1522012

Lee, M., Ban, J.-J., Kim, K. Y., Jeon, G. S., Im, W., Sung, J.-J., et al. (2016). Adiposederived stem cell exosomes alleviate pathology of amyotrophic lateral sclerosis in vitro. Biochem. Biophys. Res. Commun. 479, 434-439. doi: 10.1016/j.bbrc. 2016.09.069

Lee, P. H., Lee, J. E., Kim, H.-S., Song, S. K., Lee, H. S., Nam, H. S., et al. (2012). A randomized trial of mesenchymal stem cells in multiple system atrophy. Ann. Neurol. 72, 32-40. doi: 10.1002/ana.23612

Lee, R. H., Oh, J. Y., Choi, H., and Bazhanov, N. (2011). Therapeutic factors secreted by mesenchymal stromal cells and tissue repair. J. Cell. Biochem. 112, 3073-3078. doi: 10.1002/jcb.23250

Leng, L., Dong, X., Gao, X., Ran, N., Geng, M., Zuo, B., et al. (2020). Exosome-mediated improvement in membrane integrity and muscle function in dystrophic mice. Mol. Ther. 29, 1459-1470. doi: 10.1016/j.ymthe.2020.12.018

Li, L., Zhang, S., Zhang, Y., Yu, B., Xu, Y., and Guan, Z. (2009). Paracrine action mediate the antifibrotic effect of transplanted mesenchymal stem cells in a rat model of global heart failure. Mol. Biol. Rep. 36, 725-731. doi: 10.1007/s11033008-9235-2

Li, P., Cui, K., Zhang, B., Wang, Z., Shen, Y., Wang, X., et al. (2015). Transplantation of human umbilical cord-derived mesenchymal stems cells for the treatment of Becker muscular dystrophy in affected pedigree members. Int. J. Mol. Med. 35, 1051-1057. doi: 10.3892/ijmm.2015.2084

Li, S., Sheng, J., Hu, J. K., Yu, W., Kishikawa, H., Hu, M. G., et al. (2013). Ribonuclease 4 protects neuron degeneration by promoting angiogenesis, neurogenesis, and neuronal survival under stress. Angiogenesis 16, 387-404. doi: 10.1007/s10456-012-9322-9

Li, Y.-P., Paczesny, S., Lauret, E., Poirault, S., Bordigoni, P., Mekhloufi, F., et al. (2008). Human Mesenchymal stem cells license adult CD34+ Hemopoietic progenitor cells to differentiate into regulatory dendritic cells through activation of the Notch pathway. J. Immunol. 180, 1598-1608. doi: 10.4049/ jimmunol.180.3.1598

Li, Z., Liu, H.-Y., Lei, Q.-F., Zhang, C., and Li, S.-N. (2011). Improved motor function in dko mice by intravenous transplantation of bone marrow-derived mesenchymal stromal cells. Cytotherapy 13, 69-77. doi: 10.3109/14653249.2010. 510502

Linard, C., Brachet, M., L'homme, B., Strup-Perrot, C., Busson, E., Bonneau, M., et al. (2018). Long-term effectiveness of local BM-MSCs for skeletal muscle regeneration: a proof of concept obtained on a pig model of severe radiation burn. Stem Cell Res. Ther. 9:299. doi: 10.1186/s13287-018-1051-6

Liu, J., Saul, D., Böker, K. O., Ernst, J., Lehman, W., and Schilling, A. F. (2018). Current methods for skeletal muscle tissue repair and regeneration. Bio Med. Res. Int. 2018:e1984879. doi: 10.1155/2018/1984879

Liu, S., Ginestier, C., Ou, S. J., Clouthier, S. G., Patel, S. H., Monville, F., et al. (2011). Breast cancer stem cells are regulated by mesenchymal stem cells through cytokine networks. Cancer Res. 71, 614-624. doi: 10.1158/0008-5472.CAN-100538

Lo Sicco, C., Reverberi, D., Balbi, C., Ulivi, V., Principi, E., Pascucci, L., et al. (2017). Mesenchymal Stem cell-derived extracellular vesicles as mediators of antiinflammatory effects: endorsement of macrophage polarization: msc-derived ev promote macrophage polarization. Stem Cells Transl. Med. 6, 1018-1028. doi: 10.1002/sctm.16-0363

Longhini, A. L. F., Salazar, T. E., Vieira, C., Trinh, T., Duan, Y., Pay, L. M., et al. (2019). Peripheral blood-derived mesenchymal stem cells demonstrate immunomodulatory potential for therapeutic use in horses. PLoS One 14:e0212642. doi: 10.1371/journal.pone.0212642

Lou, G., Song, X., Yang, F., Wu, S., Wang, J., Chen, Z., et al. (2015). Exosomes derived from miR-122-modified adipose tissue-derived MSCs increase chemosensitivity of hepatocellular carcinoma. J. Hematol. Oncol.J Hematol Oncol 8:122. doi: 10.1186/s13045-015-0220-7

Luo, Z., Lin, J., Sun, Y., Wang, C., and Chen, J. (2020). Bone marrow stromal cell-derived exosomes promote muscle healing following contusion through macrophage polarization. Stem Cells Dev. 30, 167. doi: 10.1089/scd.2020.0167

Ma, Y., Dong, L., Zhou, D., Li, L., Zhang, W., Zhen, Y., et al. (2019). Extracellular vesicles from human umbilical cord mesenchymal stem cells improve nerve regeneration after sciatic nerve transection in rats. J. Cell. Mol. Med. 23, 2822-2835. doi: 10.1111/jcmm.14190

Madaro, L., Passafaro, M., Sala, D., Etxaniz, U., Lugarini, F., Proietti, D., et al. (2018). Denervation-activated STAT3-IL-6 signalling in fibro-adipogenic progenitors promotes myofibres atrophy and fibrosis. Nat. Cell Biol. 20, 917927. doi: 10.1038/s41556-018-0151-y

Maeda, Y., Yonemochi, Y., Nakajyo, Y., Hidaka, H., Ikeda, T., and Ando, Y. (2017). CXCL12 and osteopontin from bone marrow-derived mesenchymal stromal cells improve muscle regeneration. Sci. Rep. 7:3305. doi: 10.1038/s41598-01702928-1

Magatti, M., Vertua, E., Munari, S. D., Caro, M., Caruso, M., Silini, A., et al. (2017). Human amnion favours tissue repair by inducing the M1-to-M2 switch and enhancing M2 macrophage features. J. Tissue Eng. Regen. Med. 11, 2895-2911. doi: 10.1002/term.2193

Malecova, B., and Puri, P. L. (2012). "Mix of Mics"- phenotypic and biological heterogeneity of "Multipotent" muscle interstitial cells (MICs). J. Stem Cell Res. Ther. (Suppl. 11):4.

Marconi, S., Bonaconsa, M., Scambi, I., Squintani, G. M., Rui, W., Turano, E., et al. (2013). Systemic treatment with adipose-derived mesenchymal stem cells ameliorates clinical and pathological features in the amyotrophic lateral sclerosis murine model. Neuroscience 248, 333-343. doi: 10.1016/j. neuroscience.2013.05.034

Mardpour, S., Ghanian, M. H., Sadeghi-abandansari, H., Mardpour, S., Nazari, A., Shekari, F., et al. (2019). Hydrogel-mediated sustained systemic delivery of mesenchymal stem cell-derived extracellular vesicles improves hepatic regeneration in chronic liver failure. ACS Appl. Mater. Interf. 11, 37421-37433. doi: $10.1021 /$ acsami.9b10126

Markert, C. D., Atala, A., Cann, J. K., Christ, G., Furth, M., Ambrosio, F., et al. (2009). Mesenchymal stem cells: emerging therapy for duchenne muscular dystrophy. $P M R$ 1, 547-559. doi: 10.1016/j.pmrj.2009.02.013

Mead, B., Logan, A., Berry, M., Leadbeater, W., and Scheven, B. A. (2014). Paracrine-mediated neuroprotection and neuritogenesis of axotomised retinal ganglion cells by human dental pulp stem cells: comparison with human bone marrow and adipose-derived mesenchymal stem cells. PLoS One 9:e109305. doi: 10.1371/journal.pone.0109305

Mellows, B., Mitchell, R., Antonioli, M., Kretz, O., Chambers, D., Zeuner, M.-T., et al. (2017). Protein and molecular characterization of a clinically compliant amniotic fluid stem cell-derived extracellular vesicle fraction capable of accelerating muscle regeneration through enhancement of angiogenesis. Stem Cells Dev. 26, 1316-1333. doi: 10.1089/scd.2017.0089

Mirabella, T., Cilli, M., Carlone, S., Cancedda, R., and Gentili, C. (2011). Amniotic liquid derived stem cells as reservoir of secreted angiogenic factors capable of stimulating neo-arteriogenesis in an ischemic model. Biomaterials 32, 36893699. doi: 10.1016/j.biomaterials.2011.01.071

Mitchell, K. J., Pannérec, A., Cadot, B., Parlakian, A., Besson, V., Gomes, E. R., et al. (2010). Identification and characterization of a non-satellite cell muscle resident progenitor during postnatal development. Nat. Cell Biol. 12, 257-266. doi: $10.1038 /$ ncb2025

Mitchell, R., Mellows, B., Sheard, J., Antonioli, M., Kretz, O., Chambers, D., et al. (2019). Secretome of adipose-derived mesenchymal stem cells promotes skeletal muscle regeneration through synergistic action of extracellular vesicle cargo and soluble proteins. Stem Cell Res. Ther. 10:116. 10.1186/s13287-0191213-1

Montesinos, J. J., Mora-García, M., de, L., Mayani, H., Flores-Figueroa, E., GarcíaRocha, R., et al. (2013). In vitro evidence of the presence of mesenchymal stromal cells in cervical cancer and their role in protecting cancer cells from cytotoxic T cell activity. Stem Cells Dev. 22, 2508-2519. doi: 10.1089/scd.2013. 0084

Moussa, M. H., Hamam, G. G., Abd Elaziz, A. E., Rahoma, M. A., Abd El Samad, A. A., El-Waseef, D. A. A., et al. (2020). Comparative study on bone marrowversus adipose-derived stem cells on regeneration and re-innervation of skeletal 
muscle injury in wistar rats. Tissue Eng. Regen. Med. 17, 887-900. doi: 10.1007/ s13770-020-00288-y

Mozzetta, C., Consalvi, S., Saccone, V., Tierney, M., Diamantini, A., Mitchell, K. J., et al. (2013). Fibroadipogenic progenitors mediate the ability of HDAC inhibitors to promote regeneration in dystrophic muscles of young, but not old Mdx mice. EMBO Mol. Med. 5, 626-639. doi: 10.1002/emmm. 201202096

Nabavi, S. M., Arab, L., Jarooghi, N., Bolurieh, T., Abbasi, F., Mardpour, S., et al. (2019). Safety, feasibility of intravenous and Intrathecal injection of Autologous bone marrow derived mesenchymal stromal cells in patients with amyotrophic lateral sclerosis: an open label Phase I clinical trial. Cell J. 20, 592-598. doi: 10.22074/cellj.2019.5370

Nakamura, Y., Miyaki, S., Ishitobi, H., Matsuyama, S., Nakasa, T., Kamei, N., et al. (2015). Mesenchymal-stem-cell-derived exosomes accelerate skeletal muscle regeneration. FEBS Lett. 589, 1257-1265. doi: 10.1016/j.febslet.2015.03.031

Nasef, A., Mathieu, N., Chapel, A., Frick, J., François, S., Mazurier, C., et al. (2007). Immunosuppressive effects of mesenchymal stem cells: involvement of HLA-G. Transplantation 84, 231-237. doi: 10.1097/01.tp.0000267918.07906.08

Nauta, A. J., Kruisselbrink, A. B., Lurvink, E., Willemze, R., and Fibbe, W. E. (2006). Mesenchymal stem cells inhibit generation and function of both CD34+derived and monocyte-derived dendritic cells. J. Immunol. Baltim. Md 1950, 2080-2087. doi: 10.4049/jimmunol.177.4.2080

Németh, K., Leelahavanichkul, A., Yuen, P. S. T., Mayer, B., Parmelee, A., Doi, K., et al. (2009). Bone marrow stromal cells attenuate sepsis via prostaglandin E 2 dependent reprogramming of host macrophages to increase their interleukin-10 production. Nat. Med. 15, 42-49. doi: 10.1038/nm.1905

Noonan, T. J., and Garrett, W. E. (1999). Muscle strain injury: diagnosis and treatment. J. Am. Acad. Orthop. Surg. 7, 262-269. doi: 10.5435/00124635199907000-00006

Onishi, R., Ohnishi, S., Higashi, R., Watari, M., Yamahara, K., Okubo, N., et al. (2015). Human amnion-derived mesenchymal stem cell transplantation ameliorates dextran sulfate sodium-induced severe colitis in rats. Cell Transplant. 24, 2601-2614. doi: 10.3727/096368915X687570

Otabe, K., Muneta, T., Kawashima, N., Suda, H., Tsuji, K., and Sekiya, I. (2012). Comparison of Gingiva, dental pulp, and periodontal ligament cells from the standpoint of Mesenchymal stem cell properties. Cell Med. 4, 13-21. doi: 10. 3727/215517912X653319

Padhi, A. K., and Gomes, J. (2019). A molecular dynamics based investigation reveals the role of rare Ribonuclease 4 variants in amyotrophic lateral sclerosis susceptibility. Mutat. Res. 813, 1-12. doi: 10.1016/j.mrfmmm.2018.11.002

Parolini, O., Alviano, F., Bagnara, G. P., Bilic, G., Bühring, H.-J., Evangelista, M., et al. (2008). Concise review: isolation and characterization of cells from human term placenta: outcome of the first international workshop on placenta derived stem cells. Stem Cells 26, 300-311. doi: 10.1634/stemcells.2007-0594

Pascucci, L., Coccè, V., Bonomi, A., Ami, D., Ceccarelli, P., Ciusani, E., et al. (2014). Paclitaxel is incorporated by mesenchymal stromal cells and released in exosomes that inhibit in vitro tumor growth: a new approach for drug delivery. J. Control. Release Off. J. Control. Release Soc. 192, 262-270. doi: 10.1016/j. jconrel.2014.07.042

Pegtel, D. M., and Gould, S. J. (2019). Exosomes. Annu. Rev. Biochem. 88, 487-514. doi: 10.1146/annurev-biochem-013118-111902

Pereira, T., Armada-da Silva, P. A. S., Amorim, I., Rêma, A., Caseiro, A. R., Gärtner, A., et al. (2014). Effects of human Mesenchymal stem cells isolated from Wharton's Jelly of the umbilical cord and conditioned media on skeletal muscle regeneration using a myectomy model. Stem Cells Int. 2014, 1-16. doi: 10.1155/2014/376918

Pezzi, A., Amorin, B., Laureano, Á, Valim, V., Dahmer, A., Zambonato, B., et al. (2017). Effects of hypoxia in long-term in vitro expansion of human bone marrow derived Mesenchymal stem cells. J. Cell. Biochem. 118, 3072-3079. doi: $10.1002 /$ jcb. 25953

Pinheiro, C. H. D. J., de Queiroz, J. C. F., Guimarães-Ferreira, L., Vitzel, K. F., Nachbar, R. T., de Sousa, L. G. O., et al. (2012). Local injections of adipose-derived mesenchymal stem cells modulate inflammation and increase angiogenesis ameliorating the dystrophic phenotype in dystrophin-deficient skeletal muscle. Stem Cell Rev. Rep. 8, 363-374. doi: 10.1007/s12015-011-9 304-0

Pischiutta, F., Brunelli, L., Romele, P., Silini, A., Sammali, E., Paracchini, L., et al. (2016). Protection of brain injury by amniotic mesenchymal stromal cell-secreted metabolites. Crit. Care Med. 44:e01118-31. doi: 10.1097/CCM. 0000000000001864

Pisciotta, A., Riccio, M., Carnevale, G., Lu, A., De Biasi, S., Gibellini, L., et al. (2015). Stem cells isolated from human dental pulp and amniotic fluid improve skeletal muscle histopathology in mdx/SCID mice. Stem Cell Res. Ther. 6:156. doi: 10.1186/s13287-015-0141-y

Prockop, D. J., and Youn Oh, J. (2012). Mesenchymal Stem/Stromal Cells (MSCs): role as guardians of inflammation. Mol. Ther. 20, 14-20. doi: 10.1038/mt.201 1.211

Qu, Y., Zhang, Q., Cai, X., Li, F., Ma, Z., Xu, M., et al. (2017). Exosomes derived from miR-181-5p-modified adipose-derived mesenchymal stem cells prevent liver fibrosis via autophagy activation. J. Cell. Mol. Med. 21, 2491-2502. doi: $10.1111 / \mathrm{jcmm} .13170$

Rajendran, R., Gopal, S., Masood, H., Vivek, P., and Deb, K. (2013). Regenerative potential of dental pulp mesenchymal stem cells harvested from high caries patient's teeth. J. Stem Cells 8, 25-41.

Rajput, B. S., Chakrabarti, S. K., Dongare, V. S., Ramirez, C. M., and Deb, K. D. (2015). Human Umbilical cord Mesenchymal stem cells in the treatment of duchenne muscular dystrophy: safety and feasibility study in India. J. Stem Cells $10,141-156$.

Ramasamy, R., Fazekasova, H., Lam, E. W.-F., Soeiro, I., Lombardi, G., and Dazzi, F. (2007). Mesenchymal stem cells inhibit dendritic cell differentiation and function by preventing entry into the cell cycle. Transplantation 83, 71-76. doi: 10.1097/01.tp.0000244572.24780.54

Rani, S., Ryan, A. E., Griffin, M. D., and Ritter, T. (2015). Mesenchymal stem cellderived extracellular vesicles: toward cell-free therapeutic applications. Mol. Ther. 23, 812-823. doi: 10.1038/mt.2015.44

Rasmusson, I., Ringdén, O., Sundberg, B., and Le Blanc, K. (2003). Mesenchymal stem cells inhibit the formation of cytotoxic T lymphocytes, but not activated cytotoxic T lymphocytes or natural killer cells. Transplantation 76, 1208-1213. doi: 10.1097/01.TP.0000082540.43730.80

Ray, P., Devaux, Y., Stolz, D. B., Yarlagadda, M., Watkins, S. C., Lu, Y., et al. (2003). Inducible expression of keratinocyte growth factor (KGF) in mice inhibits lung epithelial cell death induced by hyperoxia. Proc. Natl. Acad. Sci. U.S.A. 100, 6098-6103. doi: 10.1073/pnas.1031851100

Riekstina, U., Cakstina, I., Parfejevs, V., Hoogduijn, M., Jankovskis, G., Muiznieks, I., et al. (2009). Embryonic stem cell marker expression pattern in human mesenchymal stem cells derived from bone marrow, adipose tissue, heart and dermis. Stem Cell Rev. Rep. 5, 378-386. doi: 10.1007/s12015-009-9094-9

Ren, H., Sang, Y., Zhang, F., Liu, Z., Qi, N., and Chen, Y. (2016). Comparative analysis of human Mesenchymal stem cells from umbilical cord, dental pulp, and menstrual blood as sources for cell therapy. Stem Cells Int. 2016, 3516574. doi: 10.1155/2016/3516574

Ringden, O., Uzunel, M., Rasmusson, I., Remberger, M., Sundberg, B., Lnnies, H., et al. (2006). Mesenchymal stem cells for treatment of therapy-resistant graft-versus-host disease. Transplantation 81, 1390-1397. doi: 10.1097/01.tp. 0000214462.63943 .14

Ripa, R. S., Haack-Sorensen, M., Wang, Y., Jorgensen, E., Mortensen, S., Bindslev, L., et al. (2007). Bone Marrow derived Mesenchymal cell mobilization by granulocyte-colony stimulating factor after acute myocardial infarction: results from the stem cells in myocardial infarction (STEMMI) trial. Circulation 116, I-24-I-30. doi: 10.1161/CIRCULATIONAHA.106.678649

Romancino, D. P., Paterniti, G., Campos, Y., De Luca, A., Di Felice, V., d’Azzo, A., et al. (2013). Identification and characterization of the nano-sized vesicles released by muscle cells. FEBS Lett. 587, 1379-1384. doi: 10.1016/j.febslet.2013. 03.012

Røsland, G., Svendsen, A., Torsvik, A., Sobala, E., Mc Cormack, E., Immervoll, H., et al. (2009). Long-term cultures of bone marrow-derived human mesenchymal stem cells frequently undergo spontaneous malignant transformation. Cancer Res. 69, 5331-5339. doi: 10.1158/0008-5472.CAN-08-4630

Rossi, D., Pianta, S., Magatti, M., Sedlmayr, P., and Parolini, O. (2012). Characterization of the conditioned medium from amniotic membrane cells: prostaglandins as key effectors of its immunomodulatory activity. PLoS One 7:e46956. doi: 10.1371/journal.pone.0046956

Saleh, A. F., Lázaro-Ibáñez, E., Forsgard, M. A.-M., Shatnyeva, O., Osteikoetxea, X., Karlsson, F., et al. (2019). Extracellular vesicles induce minimal hepatotoxicity and immunogenicity. Nanoscale 11, 6990-7001. doi: 10.1039/c8nr08 $720 \mathrm{~b}$ 
Sandonà, M., Consalvi, S., Tucciarone, L., De Bardi, M., Scimeca, M., Angelini, D. F., et al. (2020). HDAC inhibitors tune miRNAs in extracellular vesicles of dystrophic muscle-resident mesenchymal cells. EMBO Rep. 21:e50863. doi: $10.15252 /$ embr. 202050863

Sattler, C., Steinsdoerfer, M., Offers, M., Fischer, E., Schierl, R., Heseler, K., et al. (2011). Inhibition of T-cell proliferation by Murine Multipotent Mesenchymal stromal cells is mediated by CD39 expression and adenosine generation. Cell Transplant. 20, 1221-1230. doi: 10.3727/096368910X546553

Secco, M., Bueno, C., Vieira, N. M., Almeida, C., Pelatti, M., Zucconi, E., et al. (2013). Systemic delivery of human Mesenchymal stromal cells combined with IGF-1 enhances muscle functional recovery in LAMA2dy/2jDystrophic mice. Stem Cell Rev. Rep. 9, 93-109. doi: 10.1007/s12015-012-9380-9

Shabbir, A., Zisa, D., Leiker, M., Johnston, C., Lin, H., and Lee, T. (2009). Muscular dystrophy therapy by nonautologous mesenchymal stem cells: muscle regeneration without immunosuppression and inflammation. Transplantation 87, 1275-1282. doi: 10.1097/TP.0b013e3181a1719b

Shao, H., Im, H., Castro, C. M., Breakefield, X., Weissleder, R., and Lee, H. (2018). New technologies for analysis of extracellular vesicles. Chem. Rev. 118, 1917-1950. doi: 10.1021/acs.chemrev.7b00534

Shao, M., Xu, Q., Wu, Z., Chen, Y., Shu, Y., Cao, X., et al. (2020). Exosomes derived from human umbilical cord mesenchymal stem cells ameliorate IL6-induced acute liver injury through miR-455-3p. Stem Cell Res. Ther. 11:37. doi: 10.1186/s13287-020-1550-0

Sharma, A., Sane, H., Paranjape, A., Bhagawanani, K., Gokulchandran, N., and Badhe, P. (2014). Autologous bone marrow mononuclear cell transplantation in Duchenne muscular dystrophy - a case report. Am. J. Case Rep. 15, 128-134. doi: 10.12659/AJCR.890078

Shimbo, K., Miyaki, S., Ishitobi, H., Kato, Y., Kubo, T., Shimose, S., et al. (2014). Exosome-formed synthetic microRNA-143 is transferred to osteosarcoma cells and inhibits their migration. Biochem. Biophys. Res. Commun. 445, 381-387. doi: 10.1016/j.bbrc.2014.02.007

Shiue, S.-J., Rau, R.-H., Shiue, H.-S., Hung, Y.-W., Li, Z.-X., Yang, K. D., et al. (2019). Mesenchymal stem cell exosomes as a cell-free therapy for nerve injuryinduced pain in rats. Pain 160, 210-223. doi: 10.1097/j.pain.0000000000001395

Siegel, G., Kluba, T., Hermanutz-Klein, U., Bieback, K., Northoff, H., and Schäfer, R. (2013). Phenotype, donor age and gender affect function of human bone marrow-derived mesenchymal stromal cells. BMC Med. 11:146. doi: 10.1186/ 1741-7015-11-146

Silini, A. R., Cargnoni, A., Magatti, M., Pianta, S., and Parolini, O. (2015). The long path of human placenta, and its derivatives, in regenerative medicine. Front. Bioeng. Biotechnol. 3:162. doi: 10.3389/fbioe.2015.00162

Singer, N. G., and Caplan, A. I. (2011). Mesenchymal stem cells: mechanisms of inflammation. Annu. Rev. Pathol. 6, 457-478. doi: 10.1146/annurev-pathol011110-130230

Sotiropoulou, P. A., Perez, S. A., Gritzapis, A. D., Baxevanis, C. N., and Papamichail, M. (2006). Interactions between human Mesenchymal stem cells and natural killer cells. Stem Cells 24, 74-85. doi: 10.1634/stemcells.20040359

Stubbendorff, M., Deuse, T., Hua, X., Phan, T. T., Bieback, K., Atkinson, K., et al. (2013). Immunological properties of extraembryonic human mesenchymal stromal cells derived from gestational tissue. Stem Cells Dev. 22, 2619-2629. doi: $10.1089 /$ scd.2013.0043

Su, W.-H., Wang, C.-J., Fu, H.-C., Sheng, C.-M., Tsai, C.-C., Cheng, J.-H., et al. (2019). Human umbilical cord Mesenchymal stem cells extricate Bupivacaineimpaired skeletal muscle function via mitigating Neutrophil-mediated acute inflammation and protecting against fibrosis. Int. J. Mol. Sci. 20:4321. doi: 10.3390/ijms20174312

Tasso, R., Ilengo, C., Quarto, R., Cancedda, R., Caspi, R. R., and Pennesi, G. (2012). Mesenchymal stem cells induce functionally active t-regulatory lymphocytes in a Paracrine fashion and ameliorate experimental autoimmune Uveitis. Invest. Ophthalmol. Vis. Sci. 53, 786-793. doi: 10.1167/iovs.11-8211

Taylor, M., Jefferies, J., Byrne, B., Lima, J., Ambale-Venkatesh, B., Ostovaneh, M. R., et al. (2019). Cardiac and skeletal muscle effects in the randomized HOPE-Duchenne trial. Neurology 92:e00866-78. doi: 10.1212/WNL.0000000000006950

Théry, C., Witwer, K. W., Aikawa, E., Alcaraz, M. J., Anderson, J. D., Andriantsitohaina, R., et al. (2018). Minimal information for studies of extracellular vesicles 2018 (MISEV2018): a position statement of the
International Society for Extracellular Vesicles and update of the MISEV2014 guidelines. J. Extracell. Vesicles 7:1535750. doi: 10.1080/20013078.2018. 1535750

Tian, T., Zhang, H.-X., He, C.-P., Fan, S., Zhu, Y.-L., Qi, C., et al. (2018). Surface functionalized exosomes as targeted drug delivery vehicles for cerebral ischemia therapy. Biomaterials 150, 137-149. doi: 10.1016/j.biomaterials.2017.10.012

Tidball, J. G., Dorshkind, K., and Wehling-Henricks, M. (2014). Shared signaling systems in myeloid cell-mediated muscle regeneration. Development 141, 11841196. doi: 10.1242/dev.098285

Timmers, L., Lim, S. K., Arslan, F., Armstrong, J. S., Hoefer, I. E., Doevendans, P. A., et al. (2007). Reduction of myocardial infarct size by human mesenchymal stem cell conditioned medium. Stem Cell Res. 1, 129-137. doi: 10.1016/j.scr.2008. 02.002

Tolar, J., Nauta, A. J., Osborn, M. J., Panoskaltsis Mortari, A., McElmurry, R. T., Bell, S., et al. (2007). Sarcoma derived from cultured mesenchymal stem cells. Stem Cells Dayt. Ohio 25, 371-379. doi: 10.1634/stemcells.2005-0620

Toma, C., Pittenger, M. F., Cahill, K. S., Byrne, B. J., and Kessler, P. D. (2002). Human Mesenchymal stem cells differentiate to a cardiomyocyte phenotype in the adult Murine heart. Circulation 105, 93-98. doi: 10.1161/hc0102.101442

Tsai, K.-S., Yang, S.-H., Lei, Y.-P., Tsai, C.-C., Chen, H.-W., Hsu, C.-Y., et al. (2011). Mesenchymal stem cells promote formation of colorectal tumors in mice. Gastroenterology 141, 1046-1056. doi: 10.1053/j.gastro.2011.05.045

Turner, J.-E., Morrison, P. J., Wilhelm, C., Wilson, M., Ahlfors, H., Renauld, J.-C., et al. (2013). IL-9-mediated survival of type 2 innate lymphoid cells promotes damage control in helminth-induced lung inflammation. J. Exp. Med. 210, 2951-2965. doi: 10.1084/jem.20130071

Uezumi, A., Fukada, S., Yamamoto, N., Takeda, S., and Tsuchida, K. (2010). Mesenchymal progenitors distinct from satellite cells contribute to ectopic fat cell formation in skeletal muscle. Nat. Cell Biol. 12, 143-152. doi: 10.1038/ ncb2014

Uezumi, A., Ito, T., Morikawa, D., Shimizu, N., Yoneda, T., Segawa, M., et al. (2011). Fibrosis and adipogenesis originate from a common mesenchymal progenitor in skeletal muscle. J. Cell Sci. 124, 3654-3664. doi: 10.1242/jcs. 086629

Valadares, M. C., Gomes, J. P., Castello, G., Assoni, A., Pellati, M., Bueno, C., et al. (2014). Human Adipose tissue derived pericytes increase life span in utrntm1KedDmdmdx/J mice. Stem Cell Rev. Rep. 10, 830-840. doi: 10.1007/ s12015-014-9537-9

Vercelli, A., Mereuta, O. M., Garbossa, D., Muraca, G., Mareschi, K., Rustichelli, D., et al. (2008). Human mesenchymal stem cell transplantation extends survival, improves motor performance and decreases neuroinflammation in mouse model of amyotrophic lateral sclerosis. Neurobiol. Dis. 31, 395-405. doi: 10. 1016/j.nbd.2008.05.016

Wang, C., Song, W., Chen, B., Liu, X., and He, Y. (2019). Exosomes isolated from adipose-derived stem cells: a new cell-free approach to prevent the muscle degeneration associated with torn rotator cuffs. Am. J. Sports Med. 47, 3247-3255. doi: 10.1177/0363546519876323

Wang, X., Zhang, X., Ren, X.-P., Chen, J., Liu, H., Yang, J., et al. (2010). MicroRNA494 targeting both Proapoptotic and Antiapoptotic proteins protects against ischemia/reperfusion-induced cardiac injury. Circulation 122, 1308-1318. doi: 10.1161/CIRCULATIONAHA.110.964684

Winkler, T., Perka, C., Roth, P., von Agres, A. N., Plage, H., Preininger, B., et al. (2018). Immunomodulatory placental-expanded, mesenchymal stromal cells improve muscle function following hip arthroplasty. J. Cachexia Sarcopenia Muscle 9, 880-897. doi: 10.1002/jcsm.12316

Xin, H., Li, Y., Buller, B., Katakowski, M., Zhang, Y., Wang, X., et al. (2012). Exosome-Mediated Transfer of miR-133b from Multipotent Mesenchymal Stromal cells to neural cells contributes to neurite outgrowth. Stem Cells 30, 1556-1564. doi: 10.1002/stem.1129

Xin, H., Li, Y., Liu, Z., Wang, X., Shang, X., Cui, Y., et al. (2013). MiR-133b promotes neural plasticity and functional recovery after treatment of stroke with multipotent mesenchymal stromal cells in rats via transfer of exosomeenriched extracellular particles. Stem Cells 31, 2737-2746. doi: 10.1002/stem. 1409

Xu, H., Zhao, G., Zhang, Y., Jiang, H., Wang, W., Zhao, D., et al. (2019). Mesenchymal stem cell-derived exosomal microRNA-133b suppresses glioma progression via $\mathrm{Wnt} / \beta$-catenin signaling pathway by targeting EZH2. Stem Cell Res. Ther. 10:381. doi: 10.1186/s13287-019-1446-z 
Yan, X., Fu, C., Chen, L., Qin, J., Zeng, Q., Yuan, H., et al. (2012). Mesenchymal stem cells from primary breast cancer tissue promote cancer proliferation and enhance mammosphere formation partially via EGF/EGFR/Akt pathway. Breast Cancer Res. Treat. 132, 153-164. doi: 10.1007/s10549-0111577-0

Yang, S.-H., Park, M.-J., Yoon, I.-H., Kim, S.-Y., Hong, S.-H., Shin, J.-Y., et al. (2009). Soluble mediators from mesenchymal stem cells suppress T cell proliferation by inducing IL-10. Exp. Mol. Med. 41, 315-324. doi: 10.3858/emm. 2009.41.5.035

Yang, Y.-H. K., Ogando, C. R., Wang See, C., Chang, T.-Y., and Barabino, G. A. (2018). Changes in phenotype and differentiation potential of human mesenchymal stem cells aging in vitro. Stem Cell Res. Ther. 9, 131. doi: 10.1186/ s13287-018-0876-3

Yeo, R., Lai, R. C., Tan, K. H., and Lim, S. K. (2013). Exosome: a novel and safer therapeutic refinement of Mesenchymal Stem Cell. Exosomes Microvesicles 1:1. doi: $10.5772 / 57460$

Yu, B., Kim, H. W., Gong, M., Wang, J., Millard, R. W., Wang, Y., et al. (2015). Exosomes secreted from GATA-4 overexpressing mesenchymal stem cells serve as a reservoir of anti-apoptotic microRNAs for cardioprotection. Int. J. Cardiol. 182, 349-360. doi: 10.1016/j.ijcard.2014.12.043

Yukawa, H., Watanabe, M., Kaji, N., Okamoto, Y., Tokeshi, M., Miyamoto, Y., et al. (2012). Monitoring transplanted adipose tissue-derived stem cells combined with heparin in the liver by fluorescence imaging using quantum dots. Biomaterials 33, 2177-2186. doi: 10.1016/j.biomaterials.2011. 12.009

Zagoura, D. S., Roubelakis, M. G., Bitsika, V., Trohatou, O., Pappa, K. I., Kapelouzou, A., et al. (2012). Therapeutic potential of a distinct population of human amniotic fluid mesenchymal stem cells and their secreted molecules in mice with acute hepatic failure. Gut 61, 894-906. doi: 10.1136/gutjnl-2011300908

Zhang, C., Zhou, C., Teng, J.-J., Zhao, R.-L., Song, Y.-Q., and Zhang, C. (2009). Multiple administrations of human marrow stromal cells through cerebrospinal fluid prolong survival in a transgenic mouse model of amyotrophic lateral sclerosis. Cytotherapy 11, 299-306. doi: 10.1080/146532409028 06986

Zhang, L., Song, Y., Chen, L., Li, D., Feng, H., Lu, Z., et al. (2020). MiR-20acontaining exosomes from umbilical cord mesenchymal stem cells alleviates liver ischemia/reperfusion injury. J. Cell. Physiol. 235, 3698-3710. doi: 10.1002/ jcp. 29264

Zhao, C.-P., Zhang, C., Zhou, S.-N., Xie, Y.-M., Wang, Y.-H., Huang, H., et al. (2007). Human mesenchymal stromal cells ameliorate the phenotype of SOD1G93A ALS mice. Cytotherapy 9, 414-426. doi: 10.1080/14653240701376413

Zhao, Y., Wei, W., and Liu, M.-L. (2020). Extracellular vesicles and lupus nephritis - new insights into pathophysiology and clinical implications. J. Autoimmun. 115:102540. doi: 10.1016/j.jaut.2020.102540

Zhou, F., Guan, Y., Chen, Y., Zhang, C., Yu, L., Gao, H., et al. (2013). miRNA-9 expression is upregulated in the spinal cord of G93A-SOD1 transgenic mice. Int. J. Clin. Exp. Pathol. 6, 1826-1838.

Zhou, W., Fong, M. Y., Min, Y., Somlo, G., Liu, L., Palomares, M. R., et al. (2014). Cancer-secreted miR-105 destroys vascular endothelial barriers to promote metastasis. Cancer Cell 25, 501-515. doi: 10.1016/j.ccr.2014.03.007

Zhu, X., Badawi, M., Pomeroy, S., Sutaria, D. S., Xie, Z., Baek, A., et al. (2017). Comprehensive toxicity and immunogenicity studies reveal minimal effects in mice following sustained dosing of extracellular vesicles derived from HEK293T cells. J. Extracell. Vesicles 6:1324730. doi: 10.1080/20013078.2017.1324730

Zhuang, X., Xiang, X., Grizzle, W., Sun, D., Zhang, S., Axtell, R. C., et al. (2011). Treatment of brain inflammatory diseases by delivering exosome encapsulated anti-inflammatory drugs from the nasal region to the brain. Mol. Ther. 19, 1769-1779. doi: 10.1038/mt.2011.164

Zuk, P. A., Zhu, M., Ashjian, P., De Ugarte, D. A., Huang, J. I., Mizuno, H., et al. (2002). Human adipose tissue is a source of multipotent stem cells. Mol. Biol. Cell 13, 4279-4295. doi: 10.1091/mbc.e02-02-0105

Conflict of Interest: The authors declare that the research was conducted in the absence of any commercial or financial relationships that could be construed as a potential conflict of interest.

Copyright (c) 2021 Sandonà, Di Pietro, Esposito, Ventura, Silini, Parolini and Saccone. This is an open-access article distributed under the terms of the Creative Commons Attribution License (CC BY). The use, distribution or reproduction in other forums is permitted, provided the original author(s) and the copyright owner(s) are credited and that the original publication in this journal is cited, in accordance with accepted academic practice. No use, distribution or reproduction is permitted which does not comply with these terms. 